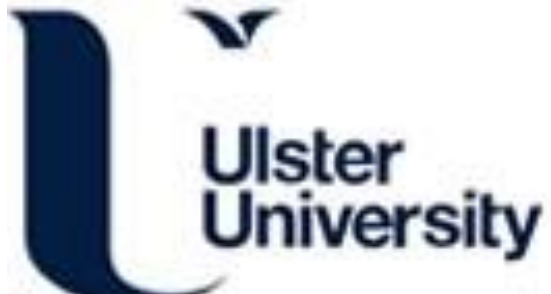

Education of healthcare professionals for preventing pressure ulcers

Porter-Armstrong, A., Moore, Z. EH., Bradbury, I., \& McDonough, S. (2018). Education of healthcare professionals for preventing pressure ulcers. Cochrane Database of Systematic Reviews, 5(5), 1-47. [CD011620]. https://doi.org/10.1002/14651858.CD011620.pub2

Link to publication record in Ulster University Research Portal

\section{Published in:}

Cochrane Database of Systematic Reviews

Publication Status:

Published (in print/issue): 25/05/2018

DOI:

10.1002/14651858.CD011620.pub2

\section{Document Version}

Publisher's PDF, also known as Version of record

\section{General rights}

Copyright for the publications made accessible via Ulster University's Research Portal is retained by the author(s) and / or other copyright owners and it is a condition of accessing these publications that users recognise and abide by the legal requirements associated with these rights.

\section{Take down policy}

The Research Portal is Ulster University's institutional repository that provides access to Ulster's research outputs. Every effort has been made to ensure that content in the Research Portal does not infringe any person's rights, or applicable UK laws. If you discover content in the Research Portal that you believe breaches copyright or violates any law, please contact pure-support@ulster.ac.uk. 


\section{(F) Cochrane Library}

Cochrane Database of Systematic Reviews

\section{Education of healthcare professionals for preventing pressure ulcers (Review)}

Porter-Armstrong AP, Moore ZEH, Bradbury I, McDonough S

Porter-Armstrong AP, Moore ZEH, Bradbury I, McDonough S.

Education of healthcare professionals for preventing pressure ulcers.

Cochrane Database of Systematic Reviews 2018, Issue 5. Art. No.: CD011620.

DOI: 10.1002/14651858.CD011620.pub2.

www.cochranelibrary.com 


\section{TABLE OF CONTENTS}

HEADER

ABSTRACT

PLAIN LANGUAGE SUMMARY

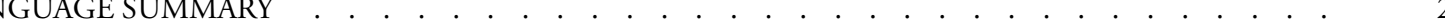

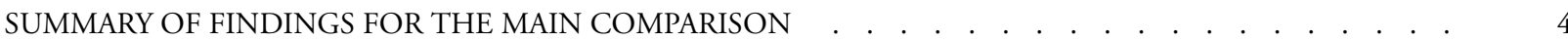

BACKGROUND . . . . . . . . . . . . . . . . . . . . . . . . . . . . . . . . . . . . . 6

OBJECTIVES . . . . . . . . . . . . . . . . . . . . . . . . . . . . . . . . . . . . . 47

METHODS . . . . . . . . . . . . . . . . . . . . . . . . . . . . . . . . . . . . . . 47

Figure 1. . . . . . . . . . . . . . . . . . . . . . . . . . . . . . . . . . . 9

Figure 2. . . . . . . . . . . . . . . . . . . . . . . . . . . . . . . . . . . . 11

RESULTS . . . . . . . . . . . . . . . . . . . . . . . . . . . . . . . . . . . . . . . 13

Figure 3. . . . . . . . . . . . . . . . . . . . . . . . . . . . . . . . . . . . . . 15

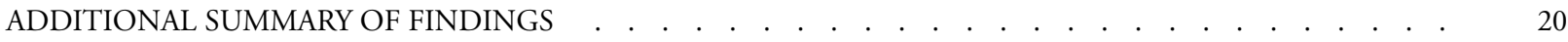

DISCUSSION . . . . . . . . . . . . . . . . . . . . . . . . . . . . . . . . . . . . . . . . $\quad . \quad 31$

AUTHORS' CONCLUSIONS . . . . . . . . . . . . . . . . . . . . . . . . . . . . . . . . . . . . . .

ACKNOWLEDGEMENTS . . . . . . . . . . . . . . . . . . . . . . . . . . . . . . . . . . . . . .

REFERENCES . . . . . . . . . . . . . . . . . . . . . . . . . . . . . . . . . . . . . . 32

CHARACTERISTICS OF STUDIES . . . . . . . . . . . . . . . . . . . . . . . . . . . . . . . . . 36

DATA AND ANALYSES . . . . . . . . . . . . . . . . . . . . . . . . . . . . . . . . . . . . . . . . . . . . . . . . . . . .

Analysis 1.1. Comparison 1 Education versus no education, Outcome 1 Knowledge hospital group. . . . . . . . . 48

Analysis 1.2. Comparison 1 Education versus no education, Outcome 2 Knowledge nursing-home group. . . . . . 49

Analysis 2.1. Comparison 2 Training, monitoring and observation vs monitoring and observation, Outcome 1 Pressure ulcer developed. . . . . . . . . . . . . . . . . . . . . . . . . . . . . . . . . . . . . . . . . . . . . . . . . .

Analysis 3.1. Comparison 3 Training monitoring and observation vs observation alone, Outcome 1 Pressure ulcer developed. . . . . . . . . . . . . . . . . . . . . . . . . . . . . . . . . . . . . . . . . . .

Analysis 4.1. Comparison 4 Monitoring and observation vs observation alone, Outcome 1 Pressure ulcer developed.

Analysis 5.1. Comparison 5 Education via didactic lecture versus video, Outcome 1 Knowledge. . . . . . . . . . . .
Analysis 6.1. Comparison 6 E-learning versus classroom teaching, Outcome 1 Correct classification of pressure ulcer photographs. . . . . . . . . . . . . . . . . . . . . . . . . . . . . . . . . . . . . . . . . . 51

APPENDICES . . . . . . . . . . . . . . . . . . . . . . . . . . . . . . . . . . . . . . . 51

CONTRIBUTIONS OF AUTHORS . . . . . . . . . . . . . . . . . . . . . . . . . . . . . . . . . . . . . . . . 58

DECLARATIONS OF INTEREST . . . . . . . . . . . . . . . . . . . . . . . . . . . . . . . . . . . . . 58

SOURCES OF SUPPORT . . . . . . . . . . . . . . . . . . . . . . . . . . . . . . . . . . . . . . . . . . . . . . . 59

DIFFERENCES BETWEEN PROTOCOL AND REVIEW . . . . . . . . . . . . . . . . . . . . . . . . . . . . . 59

Education of healthcare professionals for preventing pressure ulcers (Review) 
[Intervention Review]

\title{
Education of healthcare professionals for preventing pressure ulcers
}

\author{
Alison P Porter-Armstrong ${ }^{1}$, Zena EH Moore ${ }^{2}$, Ian Bradbury ${ }^{3}$, Suzanne McDonough ${ }^{4}$ \\ ${ }^{1}$ School of Health Sciences, University of Ulster, Belfast, UK. ${ }^{2}$ School of Nursing \& Midwifery, Royal College of Surgeons in Ireland, \\ Dublin, Ireland. ${ }^{3}$ Frontier Science Scotland, Kincraig, UK. ${ }^{4}$ Centre for Health and Rehabilitation Technologies (CHaRT), Institute \\ of Nursing and Health Research, Ulster University, Newtownabbey, UK
}

Contact address: Alison P Porter-Armstrong, School of Health Sciences, University of Ulster, Shore Road, Newtownabbey, Belfast, Co Antrim, BT37 0QB, UK. a.porter@ulster.ac.uk.

Editorial group: Cochrane Wounds Group.

Publication status and date: New, published in Issue 5, 2018.

Citation: Porter-Armstrong AP, Moore ZEH, Bradbury I, McDonough S. Education of healthcare professionals for preventing pressure ulcers. Cochrane Database of Systematic Reviews 2018, Issue 5. Art. No.: CD011620. DOI: 10.1002/14651858.CD011620.pub2.

Copyright (C) 2018 The Cochrane Collaboration. Published by John Wiley \& Sons, Ltd.

\section{A B S T R A C T}

\section{Background}

Pressure ulcers, also known as bed sores or pressure sores, are localised areas of tissue damage arising due to excess pressure and shearing forces. Education of healthcare staff has been recognised as an integral component of pressure ulcer prevention. These educational programmes are directed towards influencing behaviour change on the part of the healthcare professional, to encourage preventative practices with the aim of reducing the incidence of pressure ulcer development.

\section{Objectives}

To assess the effects of educational interventions for healthcare professionals on pressure ulcer prevention.

\section{Search methods}

In June 2017 we searched the Cochrane Wounds Specialised Register; the Cochrane Central Register of Controlled Trials (CENTRAL); Ovid MEDLINE (including In-Process \& Other Non-Indexed Citations); Ovid Embase and EBSCO CINAHL Plus. We also searched clinical trials registries for ongoing and unpublished studies, and scanned reference lists of relevant included studies as well as reviews, meta-analyses and health technology reports to identify additional studies. There were no restrictions with respect to language, date of publication or study setting.

\section{Selection criteria}

We included randomised controlled trials (RCTs) and cluster-RCTs, that evaluated the effect of any educational intervention delivered to healthcare staff in any setting to prevent pressure ulceration.

\section{Data collection and analysis}

Two review authors independently assessed titles and abstracts of the studies identified by the search strategy for eligibility. We obtained full versions of potentially relevant studies and two authors independently screened these against the inclusion criteria.

Education of healthcare professionals for preventing pressure ulcers (Review) 


\section{Main results}

We identified five studies that met the inclusion criteria for this review: four RCTs and one cluster-RCT. The study characteristics differed in terms of healthcare settings, the nature of the interventions studied and outcome measures reported. The cluster-RCT, and two of the RCTs, explored the effectiveness of education delivered to healthcare staff within residential or nursing home settings, or nursing home and hospital wards, compared to no intervention, or usual practices. Educational intervention in one of these studies was embedded within a broader, quality improvement bundle. The other two individually randomised controlled trials explored the effectiveness of educational intervention, delivered in two formats, to nursing staff cohorts.

Due to the heterogeneity of the studies identified, pooling was not appropriate and we have presented a narrative overview. We explored a number of comparisons (1) education versus no education (2) components of educational intervention in a number of combinations and (3) education delivered in different formats. There were three primary outcomes: change in healthcare professionals' knowledge, change in healthcare professionals' clinical behaviour and incidence of new pressure ulcers.

We are uncertain whether there is a difference in health professionals' knowledge depending on whether they receive education or no education on pressure ulcer prevention (hospital group: mean difference (MD) 0.30, 95\% confidence interval (CI) -1.00 to 1.60 ; 10 participants; nursing home group: MD $0.30,95 \%$ CI -0.77 to 1.37 ; 10 participants). This was based on very low-certainty evidence from one study, which we downgraded for serious study limitations, indirectness and imprecision.

We are uncertain whether there is a difference in pressure ulcer incidence with the following comparisons: training, monitoring and observation, versus monitoring and observation (risk ratio (RR) $0.63,95 \%$ CI 0.37 to 1.05 ; 345 participants); training, monitoring and observation, versus observation alone (RR $1.21,95 \%$ CI 0.60 to 2.43; 325 participants) or, monitoring and observation versus observation alone (RR 1.93, 95\% CI 0.96 to 3.88; 232 participants). This was based on very low-certainty evidence from one study, which we downgraded for very serious study limitations and imprecision. We are uncertain whether multilevel intervention versus attention control makes any difference to pressure ulcer incidence. The report presented insufficient data to enable further interrogation of this outcome.

We are uncertain whether education delivered in different formats such as didactic education versus video-based education (MD 4.60, 95\% CI 3.08 to 6.12 ; 102 participants) or e-learning versus classroom education (RR 0.92, 95\% CI 0.80 to 1.07 ; 18 participants), makes any difference to health professionals' knowledge of pressure ulcer prevention. This was based on very low-certainty evidence from two studies, which we downgraded for serious study limitations and study imprecision.

None of the included studies explored our other primary outcome: change in health professionals' clinical behaviour. Only one study explored the secondary outcomes of interest, namely, pressure ulcer severity and patient and carer reported outcomes (self-assessed quality of life and functional dependency level respectively). However, this study provided insufficient information to enable our independent assessment of these outcomes within the review.

\section{Authors' conclusions}

We are uncertain whether educating healthcare professionals about pressure ulcer prevention makes any difference to pressure ulcer incidence, or to nurses' knowledge of pressure ulcer prevention. This is because the included studies provided very low-certainty evidence. Therefore, further information is required to clarify the impact of education of healthcare professionals on the prevention of pressure ulcers.

\section{PLAIN LANGUAGESUMMARY}

\section{Educating healthcare staff to prevent pressure ulcers}

\section{Background}

Pressure ulcers, also known as bed sores or pressure sores, are often experienced by those who find it difficult to walk and spend long periods of time sitting or lying down. Pressure ulcers can range from patches of discoloured, painful skin, to open wounds that can take a long time to heal. Pressure ulcers are prone to infection and have a great impact on people's health and well being. To stop these ulcers from developing in people who are at risk, healthcare staff need to be well informed about how to prevent them. It is important to understand what type of information healthcare staff need, how it might best be delivered to them and whether education can prevent pressure ulcers from developing.

\section{Review question}

Education of healthcare professionals for preventing pressure ulcers (Review) 
We reviewed the evidence about the effect of the education of healthcare professionals on the prevention of pressure ulcers. We explored all types of education regardless of how it was delivered as long as it focused on preventing pressure ulcers. Healthcare staff included all staff working in pressure ulcer prevention from any professional background. Settings where the care was provided included hospital inpatient and outpatient departments, community clinics, patients' own homes, and residential or nursing care homes.

\section{What we found}

In June 2017 we searched for studies evaluating the effect of the education of healthcare professionals on pressure ulcer prevention, and found five relevant studies. Two studies explored the impact of education on the prevention of pressure ulcers. We are uncertain whether education of healthcare professionals makes any difference to the number of new pressure ulcers that develop. This is because the certainty of the evidence within the studies was very low.

Three studies explored the impact of education on staff knowledge of pressure ulcer prevention. The studies compared: education versus no education; components of educational intervention in a number of combinations; and education delivered in different formats. We are uncertain whether education makes any difference to staff knowledge of pressure ulcer prevention, or to the number of new pressure ulcers that develop. This is because the certainty of the evidence within the studies was very low. No study explored the impact of education on the treatment provided by health professionals. Only one study explored the secondary outcomes of interest: pressure ulcer severity, patients' views on their quality of life and carers' views on the patients' ability to carry out daily tasks independently. However, there was not enough information provided within the study to enable our independent assessment of these outcomes.

We examined the certainty of the evidence using the GRADE approach and concluded that all of the evidence was of very low certainty. Therefore we are unable to determine whether education can prevent pressure ulcers. We are also unable to determine whether education affects the knowledge that healthcare staff possess about preventing pressure ulcers.

The evidence of this review is up-to-date as of 12 June 2017.

Education of healthcare professionals for preventing pressure ulcers (Review) 


\section{SUMMARY OF FINDINGS FOR THE MAIN COMPARISON [Explanation]}

\section{Education compared to no education for preventing pressure ulcers}

Patient or population: staff caring for patients at risk of pressure ulcers

Settings: hospital and nursing homes

Intervention: education

Comparison: no education

\begin{tabular}{|c|c|c|c|c|c|c|}
\hline \multirow[t]{3}{*}{ Outcomes } & \multicolumn{2}{|c|}{ Illustrative comparative risks* $(95 \% \mathrm{Cl})$} & \multirow{3}{*}{$\begin{array}{l}\text { Relative effect } \\
(95 \% \mathrm{Cl})\end{array}$} & \multirow{3}{*}{$\begin{array}{l}\text { No of participants } \\
\text { (studies) }\end{array}$} & \multirow{3}{*}{$\begin{array}{l}\text { Quality of the evidence } \\
\text { (GRADE) }\end{array}$} & \multirow[t]{3}{*}{ Comments } \\
\hline & Assumed risk & Corresponding risk & & & & \\
\hline & No education & Education & & & & \\
\hline $\begin{array}{l}\text { Knowledge in hospital } \\
\text { group }\end{array}$ & $\begin{array}{l}\text { Mean knowledge score } \\
\text { with no education was } \\
5.7\end{array}$ & $\begin{array}{l}\text { Mean knowledge score } \\
\text { was } 0.30 \text { units higher } \\
\text { ( } 1.0 \text { lower to } 1.6 \text { higher) }\end{array}$ & & $\begin{array}{l}10 \\
\text { (1 study) }\end{array}$ & $\begin{array}{l}\oplus \bigcirc \bigcirc \bigcirc \\
\text { very low }{ }^{1}\end{array}$ & \multirow{2}{*}{$\begin{array}{l}\text { It is uncertain whether } \\
\text { there is a difference } \\
\text { in health profession- } \\
\text { als' knowledge depend- } \\
\text { ing on whether they re- } \\
\text { ceive education or no } \\
\text { education on pressure } \\
\text { ulcer prevention }\end{array}$} \\
\hline $\begin{array}{l}\text { Knowledge in nursing- } \\
\text { home group }\end{array}$ & $\begin{array}{l}\text { Mean knowledge score } \\
\text { with no education was } \\
5.1\end{array}$ & $\begin{array}{l}\text { Mean knowledge score } \\
\text { was } 0.30 \text { units higher } \\
(0.77 \text { lower to } 1.37 \\
\text { higher) }\end{array}$ & & $\begin{array}{l}10 \\
\text { (1 study) }\end{array}$ & $\begin{array}{l}\oplus \bigcirc \bigcirc \bigcirc \\
\text { very low }{ }^{1}\end{array}$ & \\
\hline
\end{tabular}

Change in health pro- Not reported

fessionals' clinical be-

haviour

Incidence of new pres- Not reported

sure ulcers

Severity of pressure ul- Not reported

cers

Patient-reported out- Not reported

comes 


\section{Carer-reported Not reported}

outcomes

*The basis for the assumed risk (e.g. the median control group risk across studies) is provided in footnotes. The corresponding risk (and its $95 \%$ confidence interval) is based on the assumed risk in the comparison group and the relative effect of the intervention (and its $95 \% \mathrm{Cl}$ ).

Cl: Confidence interval

GRADE Working Group grades of evidence

High quality: we are very confident that the true effect lies close to that of the estimate of the effect

Moderate quality: we are moderately confident in the effect estimate; the true effect is likely to be close to the estimate of effect, but there is a possibility that it is substantially different

Low quality: we are moderately confident in the effect estimate; the true effect is likely to be close to the estimate of effect, but there is a possibility that it is substantially different

Very low quality: we have very little confidence in the effect estimate; the true effect is likely to be substantially different from the estimate of effect

${ }^{1}$ Downgraded four times: serious limitations due to performance bias, detection bias and attrition bias; indirectness due to use of a non validated instrument to assess knowledge; serious imprecision due to a wide confidence interval and small sample size. 


\section{B A C K G R O U N D}

\section{Description of the condition}

A pressure ulcer (also known as a bed sore, pressure sore, decubitus ulcer or pressure injury) is "a localized injury to the skin and/or underlying tissue usually over a bony prominence, as a result of pressure, or pressure in combination with shear" (NPUAP/EPUAP/PPPIA 2014). A common international pressure ulcer classification exists that categorises pressure ulcers into four categories or stages of injury, ranging from non-blanching erythema of the skin (tissue redness that does not turn white when pressure is applied) (stage 1) to full-thickness tissue loss (stage 4 ), and two other levels of 'unstageable' and 'deep tissue injury' (NPUAP/EPUAP/PPPIA 2014).

A number of risk factors are associated with pressure ulcer development, most recently presented in a theoretical causal pathway and pressure ulcer conceptual framework (Coleman 2014). Recognising that no single factor can explain pressure ulcer susceptibility, factors such as immobility and poor perfusion have been described as direct causal factors, and factors such as moisture, poor sensory perception and nutrition have been described as indirect causal factors. These factors interplay to make some individuals particularly vulnerable or 'at risk' to pressure ulceration, however, the exact mechanisms by which this happens and which factors are of greatest importance remains unknown. Those more 'at risk' of pressure ulceration include individuals who spend prolonged periods of time sitting or lying, wheelchair users, sedentary elderly or those who are immobile (Bates-Jensen 2009; Gunningberg 2008; Thomas 2010). Pressure ulcers occur due to prolonged unrelieved exposure to externally applied mechanical forces (Gefen 2008). Those who are vulnerable to exposure to this pressure are the immobile, with older people demonstrating the highest propensity to mobility problems (Moore 2011).

Pressure ulceration has a profound impact on the health, rehabilitation, and quality of life of the individuals suffering from them (Anderson 2008; Bates-Jensen 2009; Ryan 2006; Shapcott 1999). Despite this, the prevalence of pressure ulceration remains unacceptably high, ranging from 9\% in Ireland (Moore 2011); 5\% to $32 \%$ in the UK (Kaltenthaler 2001); 18\% in Europe (Vanderwee 2007); and $12.3 \%$ in the USA (VanGilder 2009). Pressure ulcers occur in all clinical settings: acute care (mean prevalence of $21 \%$ ); long-stay (mean prevalence of $12 \%$ ); hospices $(35.7 \%$ prevalence); and community care (prevalence varies from $0.04 \%$ to $4 \%$ ) (Moore 2013). Prevalence of pressure ulcers in an intensive care setting in Australia has been shown to be as high as 50\% (Elliott 2008). Such prevalence poses a significant financial impact on healthcare services in treatment and staff costs. International studies have consistently demonstrated the high cost of treating pressure ulceration. It has been estimated that the annual cost of treating pressure ulcers is GBP 1.4 to 2.1 billion in the UK (Bennett 2004); EUR 205 million per annum in Ireland (Gethin
2005); EUR 461 million per annum in Spain (Agreda 2007); AUD 285 million per annum in Australia (Graves 2005); and USD 11 billion in the USA (Reddy 2006). In the USA, the average cost of treating a stage 4 hospital-acquired pressure ulcer alone, has been reported as being USD 129,248 and a stage 4 communityacquired pressure ulcer as USD 124,327 (Brem 2010).

Governments have recently adopted more robust positions on the prevention of pressure ulceration, for example, in the UK, pressure ulceration incidence has become a key clinical indicator in ensuring patient safety and infection control (NPSA 2010). The spotlight on pressure ulcers provides a renewed impetus to address the challenges and complexities of pressure ulceration prevention in health and social care services. It is proposed that a focus on preventative healthcare interventions would yield a more efficient use of resources, whilst also minimising the negative health and social consequences experienced by individuals 'at risk' of pressure ulceration. For example, in the USA, it has been estimated that treating people with spinal cord injuries and pressure ulceration costs USD 1.2 billion annually, as opposed to prevention, which is estimated to cost one-tenth of this sum (Byrne 1996). Given that it is thought that the majority of all pressure ulcers are preventable (DoH 2009; Pope 1999), and that prevention costs less than treatment (Stroupe 2011), a focus on preventative measures may be more cost-effective to health services (Stinson 2013).

\section{Description of the intervention}

Education of healthcare staff has been recognised as an integral component of pressure ulcer prevention (Dealey 2007). The Royal College of Nursing (RCN 2001) in their recommendations for clinical practice guidelines on pressure ulcer risk assessment and prevention, considered that education programmes should include a wide range of factors to reflect the multi-factorial and complex nature of pressure ulceration. Programmes should include information such as: risk factors and the pathophysiology of pressure ulcer development; the limitations and potential applications of risk assessment tools; skin assessment; skin care; selection, use and maintenance of pressure redistributing equipment; methods of documenting risk assessments and prevention activities; positioning to minimise pressure, shear and friction damage (including the correct use of manual handling devices); roles and responsibilities of inter-disciplinary team members in pressure ulcer management; and patient education and information giving. More recent international guidelines have been developed that broadly group the key components of preventative pressure ulceration care required by all vulnerable individuals (NPUAP/EPUAP/PPPIA 2014). The key components are classified within these guidelines as being fourfold: skin and pressure ulcer risk assessment; nutrition; repositioning; and support surfaces (bed/chair/mattress/cushion). The National Pressure Ulcer Advisory Panel has expanded upon these to develop a competency-based curriculum for use in pressure ulcer prevention (NPUAP 2013). Similarly, the Surfaces, Keep moving, Incon- 
tinence, Nutrition (SKIN) or Surfaces, Skin, Keep moving, Incontinence, Nutrition (SSKIN) care bundles offer a classification that defines and ties together best practice components in preventative pressure ulcer care (HIS 2011). These components routinely form the core aspects upon which educational interventions in pressure ulcer preventative care practices are based (Demarre 2011; Kwong 2011; Thomas 2012; Tweed 2008). However, the effectiveness of such educational programmes, what they optimally comprise, and in what format, are yet to be established.

\section{How the intervention might work}

Education is central in developing and maintaining competency, an integral component of the professional code of conduct of all health professionals (NPUAP 2013). Education also provides practitioners with the knowledge and skills needed to make wellinformed clinical decisions. Prevention of pressure ulcers is attainable through the adoption of evidence-based guidelines and high standards of care NPUAP 2013. However, in order to meet these clinical demands, healthcare professionals require specific skills and knowledge (Beeckman 2008). Educational programmes are ultimately directed towards influencing behavioural change on the part of the recipient. Thus, the underlying premise is that providing education to healthcare professionals may have the potential to enhance their knowledge and skills in pressure ulcer prevention and bring about a positive change in their clinical behaviour.

\section{Why it is important to do this review}

Education programmes may help elicit behavioural change by the healthcare professional and so support an overall reduction in the incidence and prevalence of pressure ulcer development. Studies have been conducted that report educational interventions eliciting changes across a range of constructs, such as knowledge of pressure ulcer prevention (Kwong 2011; Thomas 2012; Tweed 2008); pressure ulcer classification (Beeckman 2008); compliance with pressure ulcer clinical guidelines (Demarre 2011); and pressure ulcer risk assessment (Magnan 2008). Education of healthcare professionals in pressure ulcer prevention may, therefore, elicit positive changes in the knowledge and clinical behaviours of those individuals, leading to enhanced compliance with 'best practice' and yielding an overall reduction in prevalence and incidence of pressure ulceration. However, to date there has not been a synthesis of the evidence pertaining to the impact of education of health professionals for preventing pressure ulcers. Reviewing the evidence in order not only to determine whether education programmes for healthcare professionals can help prevent pressure ulceration, but also to understand whether the educational content, mode of delivery, and intensity and duration of input have an effect on outcomes is thus of key importance.

\section{O B J E C T I V E S}

To assess the effects of educational interventions for healthcare professionals on pressure ulcer prevention.

\section{METHODS}

\section{Criteria for considering studies for this review}

\section{Types of studies}

We included randomised controlled trials (RCTs) and clusterRCTs. In the absence of this type of evidence we planned to include non-randomised controlled trials (NRCTs), controlled before-after (CBA) studies and interrupted-time-series (ITS) studies. We excluded all other types of studies. We did not place any restrictions upon language or date of publication.

\section{Types of participants}

All healthcare staff involved in frontline pressure ulcer prevention, including medical and nursing staff, allied health professionals and healthcare assistants, based in all healthcare settings including hospital inpatients and outpatients, community-based clinics and domiciliary home care, delivering regular care to any patient group deemed 'at risk' of pressure ulceration. We excluded papers reporting upon educational interventions imparted to groups of students in any of these professions or settings.

\section{Types of interventions}

We considered all educational programmes aimed at improving clinician knowledge, changing clinical behaviour and reducing pressure ulcer incidence. These may have taken the form of direct teaching, online teaching, blended learning, workshops, short courses (series or stand alone), written educational materials, or self-directed education. We included studies describing any of the following:

1. educational intervention compared with no intervention or usual practice;

2. comparisons between different components of educational intervention;

3. comparisons between different formats of educational intervention (e.g. face-to-face training, webinars, e-learning).

\section{Types of outcome measures}

\section{Primary outcomes}


1. Change in healthcare professionals' knowledge (pre- and post-test assessment following intervention, as defined by each study).

2. Change in healthcare professionals' clinical behaviour, as defined by each study (e.g. performing routine skin inspections, enhanced repositioning or mobilisation schedules, changing sitting or lying surfaces, educating patients on skin care, instruction in pressure relief manoeuvres and transfers).

3. Incidence of new pressure ulcers (as reported by each study using numerical counts, or percentages of patients developing any pressure ulcer of any stage).

\section{Secondary outcomes}

1. Severity of new pressure ulcers (as reported by each study e.g. using International Pressure Ulcer Classification Scale (NPUAP/EPUAP/PPPIA 2014).

2. Patient-reported outcomes, as defined by each study using validated outcome measures (decreased pain e.g. McGill Pain Questionnaire, Melzack 1975); (quality of life e.g. Euroqol, EQ5D, Oemar 2013).

3. Carer-reported outcomes (enhanced independence e.g. Barthel Self Care Index, Mahoney 1965).

\section{Search methods for identification of studies}

\section{Electronic searches}

We searched the following electronic databases to identify reports of RCTs and cluster-RCTs:

1. Cochrane Wounds Specialised Register (searched 12 June 2017);

2. Cochrane Central Register of Controlled Trials

(CENTRAL; 2017, Issue 5) in the Cochrane Library (searched 12 June 2017);

3. Ovid MEDLINE including In-Process \& Other NonIndexed citations (1946 to 12 June 2017);

4. Ovid Embase (1974 to 12 June 2017);

5. EBSCO CINAHL Plus (1937 to 12 June 2017).

The search strategies for the Cochrane Wounds Specialised Register, CENTRAL, Ovid MEDLINE, Ovid Embase and EBSCO CINAHL Plus can be found in Appendix 1. We combined the Ovid MEDLINE search with the Cochrane Highly Sensitive Search Strategy for identifying randomised trials in MEDLINE: sensitivity- and precision-maximising version (2008 revision) (Lefebvre 2011). We combined the Embase search with the Ovid Embase filter developed by the UK Cochrane Centre (Lefebvre 2011). We combined the CINAHL Plus searches with the trial filters developed by the Scottish Intercollegiate Guidelines Network (SIGN 2018). There were no restrictions with respect to language, date of publication or study setting.

We also searched the following clinical trials registries:

1. ClinicalTrials.gov (www.clinicaltrials.gov/) (searched February 2018);

2. World Health Organization (WHO) International Clinical Trials Registry Platform (ICTRP) (apps.who.int/trialsearch/ Default.aspx) (searched February 2018);

3. EU Clinical Trials Register (www.clinicaltrialsregister.eu/ ctr-search/search) (searched February 2018).

Search strategies for clinical trials registries can be found in Appendix 1.

\section{Searching other resources}

We searched the bibliographies of all included trials identified by the above strategies for further relevant studies.

\section{Data collection and analysis}

We carried out data collection and analysis according to methods stated in a published protocol (Porter-Armstrong 2015).

\section{Selection of studies}

Cochrane Wounds' Information Specialist ran the electronic searches. Two review authors (APA, ZM) independently screened all titles and abstracts retrieved by the searches and excluded those that did not meet the inclusion criteria given above. If no abstract was available, we obtained the full paper and assessed it. Two review authors (APA, ZM) retrieved and assessed for eligibility the full texts of all trials classified as relevant. Disagreement between review authors was resolved by consensus, or third party adjudication $(\mathrm{SMcD})$. All full papers retrieved, but subsequently excluded, are disclosed in the Characteristics of excluded studies table, with full reasons given. A PRISMA flowchart of the data management phase of the review is shown in Figure 1 (Liberati 2009). 
Figure I. Study Flow Diagram

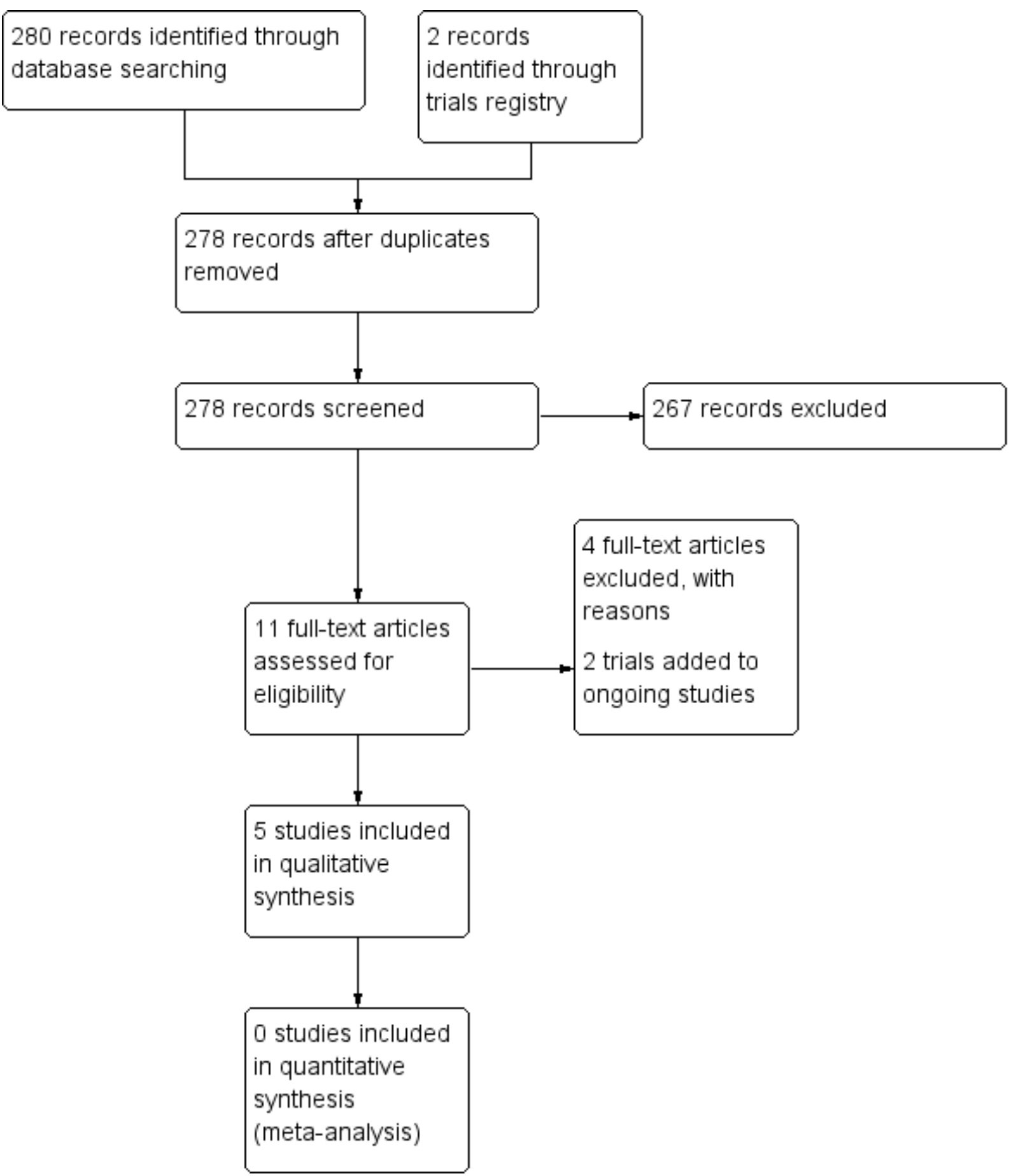




\section{Data extraction and management}

We modified the data extraction forms developed by the Effective Practice and Organisation of Care Group (EPOC 2018) and used them to extract the data from the selected studies. Two review authors (APA, ZM) independently extracted the data. We piloted the data extraction forms with a small number of studies to ensure that the correct type and level of information was being recorded. We extracted data on:

1. author, title and source;

2. date of study, country of origin;

3. study design type and details;

4. inclusion and exclusion criteria;

5. details about the intervention (e.g. format of delivery, composition of programme, length of programme, setting);

6. participant characteristics (e.g. number, education, professional training, professional background, practice setting);

7. trial quality (e.g. allocation method, outcome assessment, completeness of reporting);

8. all primary and secondary outcomes;

9. statistical analysis used;

10. outcomes data for primary and secondary outcomes;

11. funding source;

12. conflicts of interest.
We resolved any differences in opinion between the two review authors by consensus. Where necessary, we made contact with trial authors for clarification of study characteristics and data.

\section{Assessment of risk of bias in included studies}

Two review authors independently assessed risk of bias for each study using the following criteria and resolved any disagreements through consensus.

For all included studies we used the Cochrane tool for assessing risk of bias (Higgins 2011a). This tool addresses six specific domains, namely sequence generation, allocation concealment, blinding, incomplete outcome data, selective outcome reporting, and other issues (e.g. extreme baseline imbalance), see Appendix 2 for details of criteria on which we based judgements. For trials using cluster randomisation, we specifically considered recruitment bias, baseline imbalance, loss of clusters, incorrect analysis and comparability with individually randomised trials (Appendix 3). We assessed blinding and completeness of outcome data separately for each outcome. We completed a 'Risk of bias' table for each eligible study. We present assessment of risk of bias using a 'Risk of bias' summary figure (Figure 2), which presents all of the judgements in a cross-tabulation of study by entry. This display of internal validity indicates the weight the reader may give the results of each study. 
Figure 2. Risk of bias summary: review authors' judgements about each risk of bias item for each included study

\begin{tabular}{|c|c|c|c|c|c|c|c|c|c|c|c|}
\hline & 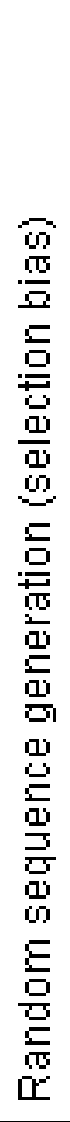 & 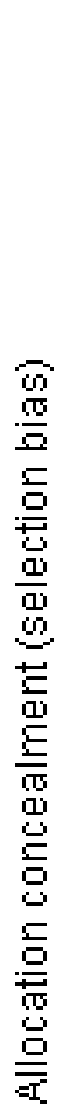 & 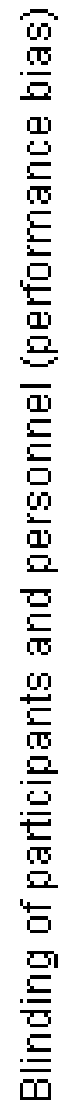 & 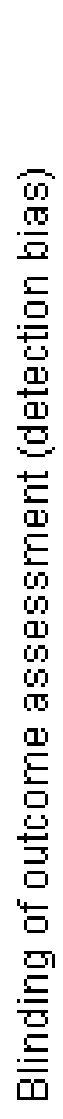 & 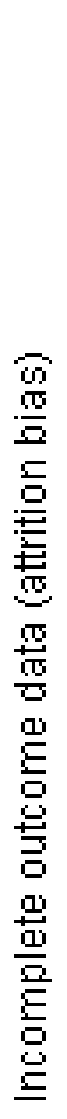 & 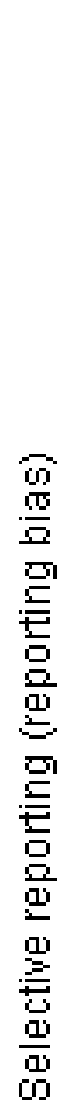 & 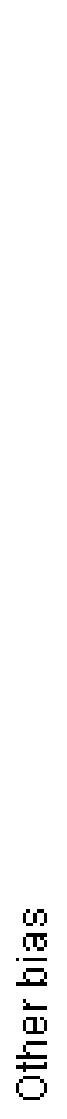 & 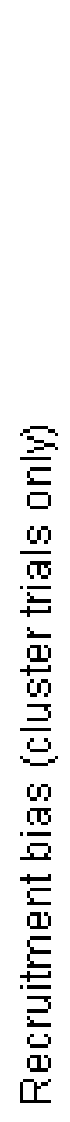 & 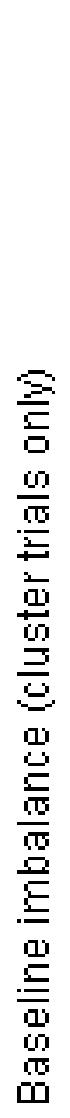 & 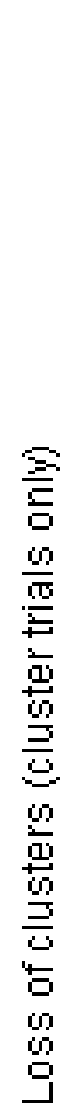 & 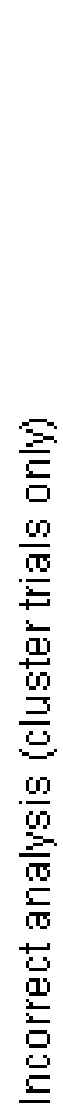 \\
\hline \multicolumn{12}{|l|}{ Bredesen 2016} \\
\hline Hayes 1994 & $?$ & $?$ & $?$ & $?$ & & & & & & & \\
\hline James 1998 & $?$ & $?$ & & & $?$ & & $?$ & & & & \\
\hline Rant 2012 & $?$ & $?$ & $?$ & & & & & & & & \\
\hline Van Gaal 2010 & $?$ & $?$ & & & & & $?$ & & & & \\
\hline
\end{tabular}


For controlled before-after (CBA) studies and interrupted-timeseries (ITS) studies we planned to use the 'Risk of bias' tool from the Cochrane EPOC group (EPOC 2013) to assess risk based upon (where appropriate to study design) allocation sequence; allocation concealment; similarity of outcome measurement; similarity of baseline characteristics; incomplete outcome data; allocation blinding; contamination; selective reporting; and other bias. Where information on risk of bias related to unpublished data or correspondence with a trial author, we planned to note this in the 'Risk of bias' table.

\section{Measures of treatment effect}

\section{Dichotomous data}

For dichotomous data, we made $2 \times 2$ contingency tables for each study, showing the number of participants with each outcome event and calculated risk ratios (RRs) with $95 \%$ confidence intervals (CIs).

\section{Continuous data}

We analysed continuous data if means and standard deviations were available, on the scale chosen in the original publication. For continuous outcomes measured identically across studies, we calculated an overall mean difference (MD) and 95\% CI. If only median and interquartile ranges were presented, we converted these to estimated mean and variance, assuming normality. Otherwise, we calculated standardised mean difference (SMD) and 95\% CI (Higgins 2011b).

\section{Ordinal data}

We planned to analyse ordinal (ordered categorical) data depending on the data presented in the original reports. If sufficient data were available from individual reports, we planned to analyse the data as ordinal data using proportional odds regression.

\section{Unit of analysis issues}

\section{Cluster-RCTs}

If cluster-RCTs had been included in the meta-analysis, we planned to first seek evidence in the publication that the authors made appropriate adjustments in their analysis to account for the clustering of data. In doubtful cases, we planned to contact the trial authors. If the error estimate had not been corrected, and necessary data were available to allow this, we planned to attempt to make the correction - if necessary using intraclass correlation coefficient estimates from other published studies. However, because there was only one cluster trial (Van Gaal 2010) we were unable to undertake meta-analysis. Therefore, we reported results for the outcomes of this review without meta analysis.

\section{Multiple trial arms}

For studies with multiple intervention groups, we made multiple pair-wise comparisons between all possible pairs of intervention groups, which were presented as separate analyses.

\section{Interrupted time series studies}

If required, and if sufficient data were available in the published study or from the original trial authors, we planned to re analyse results to account for unit of analysis errors in ITS designs.

\section{Dealing with missing data}

If summary items such as standard errors were missing from the published report, we contacted the trial authors in order to verify key study characteristics and obtain missing numerical outcome data where possible. If missing data were unobtainable, we planned to present the available-cases result together with two alternatives; first imputing missing data by the treatment arm mean, and second imputing missing data by the control arm mean. In both cases, we planned to analyse data outside of Review Manager 5 (Review Manager 2014) to allow study weights from the available-cases analysis to be used in order to avoid inflating the apparent precision of the estimates.

Where the missing data were thought likely to introduce a risk of bias, we noted this in the 'Risk of bias' table and planned to explore the impact of including such studies in the overall assessment of results by a sensitivity analysis.

\section{Assessment of heterogeneity}

We planned to use the $I^{2}$ statistic (Higgins 2003) to measure heterogeneity among the trials in each analysis and would have reported our findings for each analysis. If we identified unexplained heterogeneity, that is, $\mathrm{Chi}^{2}$ test significant at the level of $0.1, \mathrm{I}^{2}$ greater than $50 \%$, and changes in direction of effect, we planned to first explore clinical explanations for such heterogeneity, for example with important subgroups. If we were unable to explain the heterogeneity clinically, then we planned to use random-effects analysis or narrative review. 


\section{Assessment of reporting biases}

We planned to assess reporting bias using Cochrane guidelines (Sterne 2010). If sufficient studies were found (at least 10), we planned to use funnel plots to investigate asymmetry in respect of publication and selective reporting bias and conduct Egger Tests to assess for bias.

\section{Data synthesis}

We planned to use Review Manager 5 (Review Manager 2014) to perform meta-analysis of the included studies separately for continuous, dichotomous and ordinal outcomes, and planned to present the meta-analysis using forest plots and statistical summaries. We planned to use a fixed-effect model unless there were clinical or statistical reasons (I ${ }^{2}$ statistic greater than $50 \%$ ) to suspect significant heterogeneity, in which case we planned to use random-effects analysis $\left(\mathrm{I}^{2} \leq 75 \%\right)$ or narrative review $\left(\mathrm{I}^{2}>75 \%\right.$ or clinical heterogeneity).

\section{Subgroup analysis and investigation of heterogeneity}

We planned to analyse potential sources of heterogeneity using the following subgroup analyses:

1. type of setting (community, hospital, inpatient, outpatient);

2. type of healthcare professional (medical staff, nursing staff, allied health professional);

3. type of education approach (face-to-face, e-learning, webinars).

\section{Sensitivity analysis}

We planned to perform sensitivity analyses to examine how the results of any meta-analysis would change under the following assumptions:

1. we planned to assess the robustness of results by only including studies assessed as low risk of bias. We planned to exclude trials deemed most susceptible to bias based upon the quality assessment, particularly those with inadequate allocation concealment, uncertain or unblinded outcome assessment, or incomplete outcome data;

2. we planned to explore the effect of inadequate correction for clustering by varying the assumed intracluster correlation coefficient, and by omitting studies whose primary report had apparently failed to correct for clustering;

3. we planned to explore the effect of inadequate correction for auto correlation in ITS studies by omitting studies whose primary report had apparently failed to correct for auto correlation;

4. we planned to assess the effect of missing data by, where possible (a) restricting the analysis to only studies without missing data, and (b) restricting the analysis to complete studies plus those that had attempted to adjust for missing data.

\section{'Summary of findings' tables}

We have presented 'Summary of findings' tables for the following primary outcomes: healthcare professionals' knowledge (pre- and post-test assessment following intervention, and comparisons between the control and experimental group post-test), health professionals' clinical behaviour, and pressure ulcer incidence (proportion of patients developing a new ulcer). We have also included the following secondary outcomes in the 'Summary of findings' tables: severity of new pressure ulcers, patient-reported outcomes and carer-reported outcomes. We assessed the quality of the published evidence using the GRADE protocol (Guyatt 2011) against the following five key issues:

1. limitations in the design and implementation of available studies suggesting high likelihood of bias;

2. indirectness of evidence (indirect population, intervention, control, outcomes);

3. unexplained heterogeneity or inconsistency of results (including problems with subgroup analyses);

4. imprecision of results (including wide confidence intervals);

5. high probability of publication bias (Schünemann 2011).

\section{RE S U L T S}

\section{Description of studies}

See Characteristics of included studies; Characteristics of excluded studies.

\section{Results of the search}

The search yielded 282 citations. Two review authors examined the abstracts of all the papers, independently, to assess for potential relevance. Of these, we retrieved eleven studies for further assessment and after examination, five studies met the inclusion criteria (Bredesen 2016; Hayes 1994; James 1998; Rantz 2012; Van Gaal 2010); four studies were excluded (Danchaivijitr 1995; Esche 2015; Rantz 2001; Shannon 2012); and two trials were retrieved through searching of trial registers and identified as relevant ongoing studies (IRCT2017080935602N1; NCT02270385), refer to Characteristics of ongoing studies for more details about these trials. See PRISMA flow chart (Figure 1).

\section{Included studies}

We have included five studies in this review (Bredesen 2016; Hayes 1994; James 1998; Rantz 2012; Van Gaal 2010). See Characteristics of included studies. Three studies purported to be cluster-RCTs, conducted in the Netherlands (Van Gaal 2010), the UK (James 1998), and the USA (Rantz 2012); of which only one 
was truly a cluster-RCT (Van Gaal 2010), and two were parallel group RCTs (James 1998; Rantz 2012). The other two studies were also parallel-group RCTs undertaken in the USA (Hayes 1994) and Norway (Bredesen 2016).

\section{Populations}

The studies were undertaken in the following settings: two acute care hospitals and four nursing homes in Norway (Bredesen 2016), an urban acute care hospital in the USA (Hayes 1994), 37 residential homes in the UK (James 1998), 58 nursing homes in the USA (Rantz 2012), and 20 hospital and nursing home wards in the Netherlands (Van Gaal 2010).

In Bredesen 2016, Hayes 1994 and Van Gaal 2010, the participants were nursing staff (registered nurses, licensed practical nurses and nursing assistants) and James 1998 described the participants as nursing staff. In Rantz 2012, the participants were owners of facilities, nursing and administrative facility staff, and direct-care staff. However, the intervention was directed at the leaders of the facilities.

James 1998 and Rantz 2012 did not provide information pertaining to the sample size of the intervention target population. The mean sample size in the remaining three studies (Bredesen 2016; Hayes 1994; Van Gaal 2010) was 327 participants (SD 361; min 44, max 837).

Neither James 1998 nor Rantz 2012 provided data regarding the age or gender distribution of the intervention target participants. In Hayes 1994, the mean age of the participants was 33.3 years (SD 10.3 years, min 20 years, $\max 69$ years), and $81.2 \%(\mathrm{n}=91)$ were female. In Van Gaal 2010, the mean age of the participants was 38 years (SD 10.7 years), and 89\% ( $\mathrm{n}=411)$ were female. Bredesen 2016, provided data on gender distribution only and $97.7 \%(n=43)$ of the participants were female.

\section{Interventions}

Bredesen 2016 randomly assigned nurses to one of two groups. Each participant in the e-learning group completed an individual, computer-based training module on pressure ulcer risk assessment and classification. The classroom group received the same training module content on pressure ulcer risk assessment and classification, delivered through a 45-minute lecture format by an experienced nurse using a PowerPoint presentation. Similarly, Hayes 1994 randomly assigned nurses to one of two groups. The intervention group received a 40 -minute instructional educational session, based on pressure ulcer prevention and treatment information, and the control group viewed a 25-minute video on general skin care for hospitalised patients.

In James 1998, there were three study groups, and nursing homes were randomised to one of the three groups. Although termed as a cluster randomised trial, this was a parallel RCT with the outcomes of interest at a nursing home level, rather than at the level of the individual patient, and nursing homes were the unit of randomisation. The intervention group received three elements: training, monitoring and observation. Training comprised a twohour, interactive educational session delivered by a district nurse covering pressure ulcer risk assessment, grading and preventative strategies including nutrition, continence, mobility, and moving and handling. Monitoring comprised a district nurse-led educational session on pressure ulcer risk assessment and grading only. Observation comprised data collection via a point prevalence assessment at baseline, six, 12 and 18 months.

Rantz 2012 was also termed a cluster randomised trial, however similar to James 1998, this was a parallel RCT as the outcomes were measured at the nursing home level and the unit of randomisation was the nursing homes. Outcomes were compared between the control or intervention groups of the study. The multilevel intervention targeted three levels of staff responsible for operating a nursing facility: owners, nursing and administrative facility staff, and direct-care staff. Owners were asked, at least for the duration of the study, to (1) provide consistent nursing and administrative leadership, (2) adopt the elements of change (EC) into their management practices, and to actively support and encourage (3) the use of team and group processes for decision-making affecting resident care, (4) the use of a quality-improvement programme and (5) the efforts of staff to focus on performing the basics of care, including ambulation, nutrition and hydration, toileting, bowel regularity, preventing skin breakdown and managing pain. The trial investigators provided a detailed intervention manual and two text books to the leaders of each intervention facility. The research nurse observed direct-care staff at work and then met with them and nursing administrative staff in quality-improvement teams. These groups tailored care systems and practices outlined in the intervention manual to fit their situation, anchoring them into their facility's care routines.

Van Gaal 2010 used cluster randomisation to allocate five hospital wards and five nursing home wards to the intervention group, and five hospital wards and five nursing home wards to the control group. The intervention consisted of small-scale, educational meetings, educational materials and outreach visits, delivered to all nurses in the participating wards in the intervention group. Outcomes were measured at the individual patient level.

\section{Comparisons}

The control group in the original protocol of Bredesen 2016 were to receive no additional education. However, due to "massive dropout" ( $p$ 192) this control group was excluded from the study and was not reported upon. The control group in Hayes 1994 received monthly, videotaped, in-service training and reading materials about aging and physical assessment of elderly residents, topics that were not directly related to quality-improvement strategies.

James 1998 used two control groups, one of monitoring and obser- 
vation, and one of observation only, as the comparators. Monitoring comprised a district nurse-led educational session on pressure ulcer risk assessment and grading only. Observation comprised data collection via a point prevalence assessment at baseline, six, 12 and 18 months.

The control group in Rantz 2012 received a monthly mailing of general educational material pertaining to elderly care, alongside a monthly telephone call from the co-investigator to answer any questions relating to the materials, whereas the Van Gaal 2010 control group received no intervention at all.

\section{Outcomes}

All studies reported at least one of the primary outcomes of interest for this review. However, these outcomes varied across all five studies and included pressure ulcer development (Rantz 2012); pressure ulcer development, functional dependency and self-reported quality of life (James 1998); and knowledge of pressure ulcer risk, classification, assessment and treatment (Bredesen 2016; Hayes 1994; Van Gaal 2010).

\section{Excluded studies}

We excluded four studies from this review: two studies because they were not RCT design (Danchaivijitr 1995; Esche 2015), one because the study purpose was different from the focus of this review (Rantz 2001), and the other as trial participants in both groups received the educational intervention before the study began (Shannon 2012). See Characteristics of excluded studies.

\section{Risk of bias in included studies}

All five studies were at high or unclear risk of bias. We have presented details in separate 'Risk of bias' tables for each of the five studies (see Characteristics of included studies) and in a summary table and graph (Figure 2; Figure 3). As no meta-analyses were performed, the one cluster randomised controlled trial was assessed against the first 4 of the 5 additional risk of bias criteria for cluster trials (Appendix 3).

Figure 3. Risk of bias graph: review authors' judgements about each risk of bias item presented as percentages across all included studies

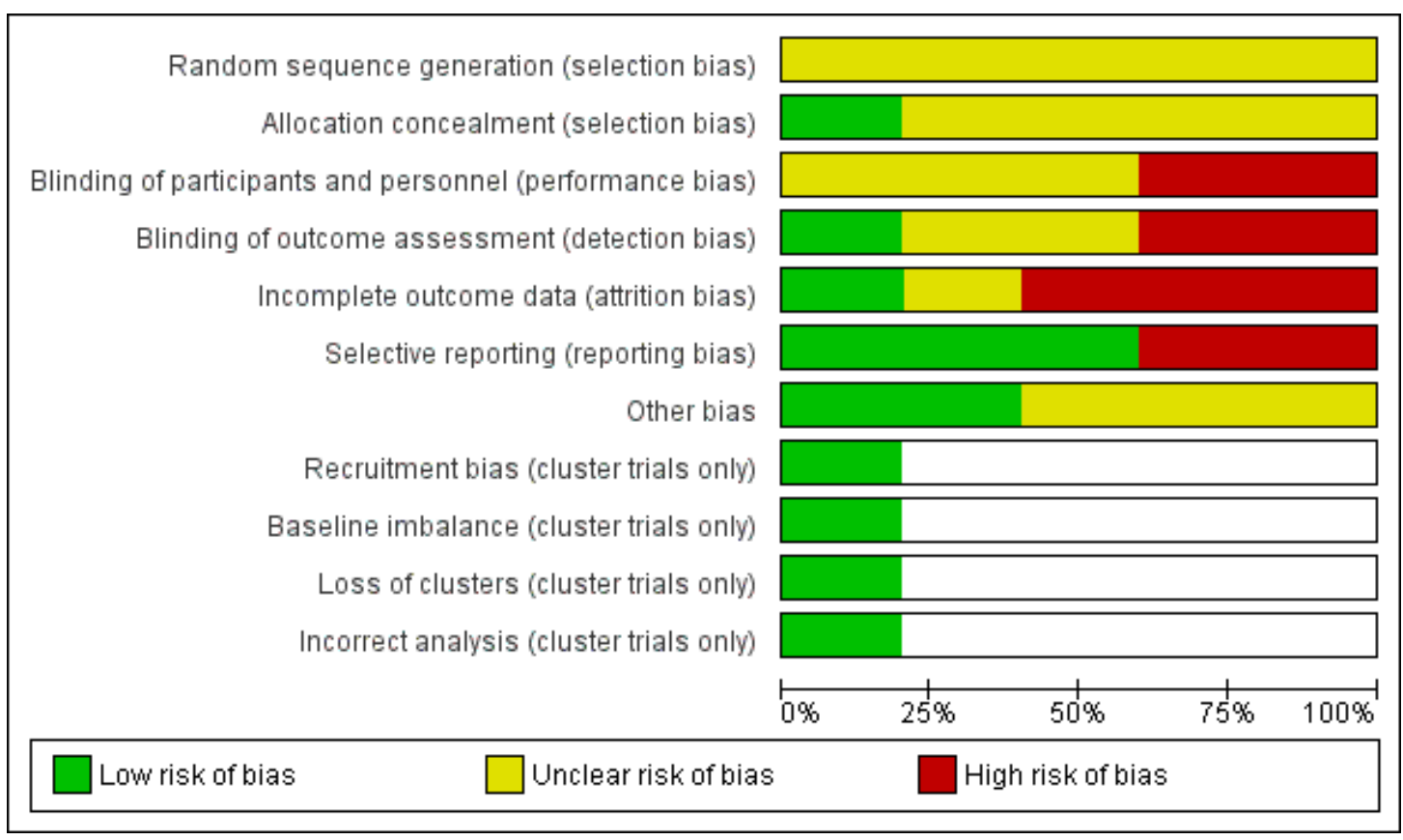

Education of healthcare professionals for preventing pressure ulcers (Review) 


\section{Allocation}

All five studies reported methods of randomisation. In Bredesen 2016, the principal investigator assigned participants using block randomisation to the e-learning or classroom-based group. Similarly in Hayes 1994, one of the investigators assigned participants randomly to the experimental or control group. In James 1998, allocation to study group was at the level of the nursing home which was also the unit of analysis. Rantz 2012 randomised owners of nursing homes to either the intervention or control group, then randomly invited individual nursing homes to participate and if they agreed, assigned them to the group designation based upon the owner; again the nursing home was the unit of analysis. Van Gaal 2010 used cluster randomisation, where allocation was by ward, stratified by centre and type of ward.

Allocation concealment was reported in Bredesen 2016 through the use of closed, opaque, numbered envelopes to conceal group allocation. The other four studies did not report allocation concealment.

\section{Blinding}

James 1998 disclosed that participating staff were aware of group allocation and we thus judged it to be at high risk for performance bias. Similarily judged as high risk was Van Gaal 2010, as participants would have known their group allocation based upon whether they received the educational intervention or not. It is unclear whether blinding of participants occurred in Bredesen 2016; Hayes 1994 or Rantz 2012.

It is reasonable to assume that blinding of participants and staff would have been difficult to achieve, as it would have been clear which group the participant was in. Nonetheless, blinded outcome assessment would have been possible in terms of pressure ulcer development, functional dependency, self-reported quality of life and knowledge scores, as these outcomes were gathered using data-collection instruments, which could have been anonymised regarding study allocation.

Blinding of outcome assessment was reported in only one study (Rantz 2012). One study reported that they did not undertake blinded outcome assessment (James 1998). We judged Van Gaal 2010 to be at high risk as, at each ward, one nurse was responsible for the distribution and collection of the questionnaires, so we judged it likely that this nurse knew group allocation. Blinding of outcome assessment was not reported in Bredesen 2016 or Hayes 1994 and we thus judged them to be at unclear risk of bias.

\section{Incomplete outcome data}

We judged Van Gaal 2010 to be at high risk of attrition bias, as the actual attrition rates in the study were judged to be higher than acceptable. In the pre-intervention phase, the response rates for the questionnaires were: $80 \%$ intervention group and $72 \%$ control (hospital wards), and 66\% intervention group and $71 \%$ con- trol (nursing home wards). In the postintervention phase, the response rates for the questionnaires were: $49 \%$ intervention group and $87 \%$ control (hospital wards), and $58 \%$ intervention group and 56\% control (nursing home wards). In Rantz 2012, there was also a dropout rate for response to the survey employed (intervention group $71 \%$ baseline and $63 \%$ study end; control group $65 \%$ baseline; $53 \%$ study end), thus we judged it to be at high risk of attrition bias. Similarily, we also judged Bredesen 2016 to be at high risk of attrition bias, with an overall drop out rate of $59 \%$ at the three-month, postintervention phase (e-learning group 52\% baseline and 23\% study end; classroom group 48\% baseline and $18 \%$ study end). We judged James 1998 as unclear as there was insufficient information provided to make a full assessment. Only Hayes 1994 was judged to be at low risk of attrition bias.

\section{Selective reporting}

We judged Bredesen 2016 at high risk of selective reporting bias as the study authors excluded the original control group comprising no additional education from the study report due to dropout and only reported on the two active education arms of the study. Further, whilst the study protocol stated that they had planned a 24-week measurement, they did not report it. Another study did not report all the outcomes described in the methods section in sufficient detail to allow full interrogation of the data, therefore we have scored this accordingly, at high risk of bias (James 1998). The other three studies (Hayes 1994; Rantz 2012; Van Gaal 2010) reported on all the outcomes measured and therefore we judged them to be at low risk of reporting bias.

\section{Other potential sources of bias}

No other potential sources of bias were apparent from two of the studies (Hayes 1994; Rantz 2012). Participants in Bredesen 2016 were not asked about their computer proficiency in using an elearning platform to access training and thus, as a potential source of bias, we assessed it as unclear. James 1998 provided limited information pertaining to the characteristics of the nursing staff participants and thus, as a potential source of bias, we assessed it as unclear. Van Gaal 2010 used a non-standardised outcome measure to gather data and thus, as a potential source of bias, we assessed it as unclear.

\section{Effects of interventions}

See: Summary of findings for the main comparison Education compared to no education for preventing pressure ulcers; Summary of findings 2 Training, monitoring and observation compared to monitoring and observation for preventing pressure ulcers; Summary of findings 3 Training, monitoring and observation compared to observation alone for preventing pressure ulcers; Summary of findings 4 Monitoring and observation compared to observation alone for preventing pressure ulcers; 
Summary of findings 5 Didactic education versus video education for preventing pressure ulcers; Summary of findings 6 E-learning versus classroom education for preventing pressure ulcers

\section{Comparison I. Education versus no education (I trial, 20 wards from 4 hospitals and 6 nursing homes)}

\section{Primary outcome}

\section{Changes in health professionals' knowledge}

One study (Van Gaal 2010) reported the primary outcome: change in healthcare professionals' knowledge.

Van Gaal 2010 evaluated change in nurses' knowledge using a 20-item pressure ulcer knowledge test developed for the study, at baseline and one year post baseline. Due to differences in nurses' characteristics between hospitals and nursing homes, the study authors analysed the data for hospital wards and nursing home wards separately. The study authors did not undertake any analysis for the effect of clustering. We have reported the data from the study as further analysis was not possible. We classed this study at high risk of bias, since the $95 \%$ CIs would be narrower than they would have been had the correct analysis been undertaken. It is unclear whether education versus no education makes any difference to health professionals' knowledge, as we assessed the certainty of the evidence as very low (downgraded twice for serious limitations due to performance bias, detection bias and attrition bias, and downgraded twice for indirectness due to use of a non validated instrument to assess knowledge, and imprecision due to a wide confidence interval) see Summary of findings for the main comparison. The mean knowledge score for the hospital participants was 6 (SD: 1.1) for the education group and 5.7 (SD: 0.99 ) for the no-education group (MD $0.30,95 \% \mathrm{CI}-1.00$ to $1.60 ; 10$ participants; Analysis 1.1). The mean post-test knowledge score for the nursing home participants was 5.4 (SD: 0.96) for the education group and 5.1 (SD: 0.76 ) for the no-education group (MD 0.30, 95\% CI -0.77 to 1.37; 10 participants; Analysis 1.2) (pre-test knowledge scores were 5.0 (0.84) and 4.8 (0.78) respectively).

\section{Changes in health professionals' clinical behaviour}

Not reported

\section{Incidence of new pressure ulcers}

Not reported

\section{Secondary outcomes}

\section{Severity of new pressure ulcers}

Not reported

\section{Patient-reported outcomes}

Not reported

\section{Carer-reported outcomes}

Not reported

\section{Comparison 2. Comparisons between different components of educational intervention: training, monitoring and observation versus monitoring and observation (I trial, 37 residential homes with 345 residents)}

\section{Primary outcomes}

Change in health professionals' knowledge

Not reported

Change in health professionals' clinical behaviour

Not reported

\section{Incidence of new pressure ulcers}

One study (James 1998) reported the primary outcome: incidence of pressure ulcers.

James 1998 used the Norton scale (Norton 1975) and research nurse skin assessments at baseline, 6, 12 and 18 months, to calculate incidence of pressure ulcers. It is unclear whether training, monitoring and observation versus monitoring and observation makes any difference to pressure ulcer incidence, as we assessed the certainty of the evidence as very low (downgraded twice for serious limitations due to performance bias, detection bias and outcome reporting bias, and downgraded once for imprecision due to a wide confidence interval) see Summary of findings 2. In the training, monitoring and observation group, $11.4 \%$ of patients (25/219) developed a pressure ulcer during the study period, whereas in the monitoring and observation group $18 \%$ of patients $(23 / 125)$ developed a pressure ulcer during the study period (RR 0.63, 95\% CI 0.37 to 1.05 ; 345 participants; Analysis 2.1).

\section{Secondary outcomes}

James 1998 measured the following secondary outcomes.

\section{Severity of new pressure ulcers}

James 1998 measured severity of pressure sores using the David classification of pressure sore severity (David 1983), a four-stage grading system, used weekly by the staff and recorded by the research nurse assessor at baseline, 6, 12 and 18 months. The study report did not present any data on this outcome to enable further evaluation. 


\section{Patient-reported outcomes}

James 1998 used Euroqol (Oemar 2013) to measure the self-assessed quality of life of the residents at all four time points and reported no differences in scores between the groups of residents during the 18-month study period. The report presented insufficient data to enable further interrogation of this outcome.

\section{Carer-reported outcomes}

James 1998 used the Bathel Index (Mahoney 1965) to measure the functional dependency level of the residents at all four time points throughout the study. The trial author reported no differences, but there were insufficient data within the report to further interrogate this outcome.

\section{Comparison 3. Comparisons between different components of educational intervention: training, monitoring and observation versus observation alone ( I trial, 37 residential homes with 325 residents)}

\section{Primary outcomes}

\author{
Change in health professionals' knowledge \\ Not reported
}

\author{
Change in health professionals' clinical behaviour \\ Not reported
}

\section{Incidence of new pressure ulcers}

One study (James 1998) reported the primary outcome: incidence of pressure ulcers.

James 1998 used the Norton scale (Norton 1975) and research nurse skin assessments at baseline, 6, 12 and 18 months, to calculate incidence of pressure ulcers. It is unclear whether training, monitoring and observation versus observation alone makes any difference to pressure ulcer incidence, as we assessed the certainty of the evidence as very low (downgraded twice for serious limitations due to performance bias, detection bias and outcome reporting bias, and downgraded once for imprecision due to a wide confidence interval) see Summary of findings 3. In the training, monitoring and observation group $11.4 \%$ of patients (25/219) developed a pressure ulcer during the study period, whereas in the observation group $10 \%$ of patients $(10 / 106)$ developed a pressure ulcer during the study period (RR $1.21,95 \%$ CI 0.60 to 2.43 ; 325 participants); Analysis 3.1).

\section{Secondary outcomes}

James 1998 measured the following secondary outcomes.

\section{Severity of new pressure ulcers}

James 1998 measured severity of pressure ulcers using the David classification of pressure sore severity (David 1983), a four-stage grading system, used weekly by the staff and recorded by the research nurse assessor at baseline, 6,12 and 18 months. The study report did not present any data on this outcome to enable further evaluation.

\section{Patient-reported outcomes}

James 1998 used Euroqol (Oemar 2013) to measure the self-assessed quality of life of the residents at all four time points and reported no differences in scores between the groups of residents during the 18-month study period. The report presented insufficient data to enable further interrogation of this outcome.

\section{Carer-reported outcomes}

James 1998 used the Bathel Index (Mahoney 1965) to measure the functional dependency level of the residents at all four time points throughout the study. The trial author reported no differences, but the report presented insufficient data to further interrogate this outcome.

\section{Comparison 4. Comparisons between different components of educational intervention: monitoring and observation versus observation alone (I trial, 37 residential homes with 232 residents)}

\section{Primary outcomes}

\section{Change in health professionals' knowledge}

Not reported

\section{Change in health professionals' clinical behaviour}

Not reported

\section{Incidence of new pressure ulcers}

One study (James 1998) reported the primary outcome: incidence of pressure ulcers.

James 1998 used the Norton scale (Norton 1975) and research nurse skin assessments at baseline, 6, 12 and 18 months, to calculate incidence of pressure ulcers. It is unclear whether monitoring and observation versus observation alone makes any difference to pressure ulcer incidence, as we assessed the certainty of the evidence as very low (downgraded twice for serious limitations due to performance bias, detection bias and outcome reporting bias, and downgraded once for imprecision due to a wide confidence interval) see Summary of findings 4 . In the monitoring and observation group $18 \%$ of patients $(23 / 125)$ developed a pressure ulcer during the study period, whereas in the observation group $10 \%$ of patients (10/106) developed a pressure ulcer during the study 
period (RR 1.93, 95\% CI 0.96 to 3.88; 232 participants; Analysis 4.1).

\section{Secondary outcomes}

James 1998 measured the following secondary outcomes.

\section{Severity of new pressure ulcers}

James 1998 measured severity of pressure ulcers using the David classification of pressure sore severity (David 1983), a four-stage grading system, used weekly by the staff and recorded by the research nurse assessor at baseline, 6, 12 and 18 months. The study report did not present any data on this outcome to enable further evaluation.

\section{Patient-reported outcomes}

James 1998 used Euroqol (Oemar 2013) to measure the self-assessed quality of life of the residents at all four time points and reported no differences in scores between the groups of residents during the 18-month study period. The report presented insufficient data to enable further interrogation of this outcome.

\section{Carer-reported outcomes}

James 1998 used the Bathel Index (Mahoney 1965) to measure the functional dependency level of the residents at all four time points throughout the study. The trial author reported no differences, but the report presented insufficient data to further interrogate this outcome.

\section{Comparison 5. Comparisons between different components of educational intervention: multilevel intervention versus attention control (I trial, 58 nursing homes)}

\section{Primary outcomes}

\section{Change in health professionals' knowledge}

Not reported

\section{Change in health professionals' clinical behaviour}

Not reported

\section{Incidence of new pressure ulcers}

One study (Rantz 2001) reported the primary outcome: odds of pressure ulcer development.

Rantz 2012 used repeated measures analysis and applied a logistic regression model to calculate the odds ratio of pressure ulcer development between the study groups. The trial authors reported a reduction in pressure ulcer incidence, however, the report presented insufficient data to enable further interrogation of this outcome.
Using the GRADE assessment, this was assessed as low certainty evidence (downgraded twice for multiple issues with risk of bias).

\section{Secondary outcomes}

Severity of new pressure ulcers

Not reported

\section{Patient-reported outcomes}

Not reported

\section{Carer-reported outcomes}

Not reported

\section{Comparison 6. Comparison between different formats of education: didactic education versus video education ( I trial, I 02 participants)}

\section{Primary outcome}

\section{Change in healthcare professionals' knowledge}

One study (Hayes 1994) reported the primary outcome: change in healthcare professionals' knowledge.

Hayes 1994 evaluated changes in nurses' knowledge of pressure ulceration using a 100-item, true-false questionnaire developed for the study pre- and postintervention, a higher score indicated better knowledge. It is unclear whether education delivered via didactic lecture versus education delivered via video makes any difference to health professionals' knowledge, as we assessed the certainty of the evidence as very low (downgraded once for serious limitations due to unclear risk of selection bias, performance bias and detection bias, and downgraded twice for serious imprecision due to small sample size and a wide confidence interval) see Summary of findings 5 . The mean knowledge score for the didactic lecture group was 84.62 (SD: 4.01) and for the video education group was 89.22 (SD: 3.80); (MD 4.60, 95\% CI 3.08 to 6.12; 102 participants; Analysis 5.1).

Change in healthcare professionals' clinical behaviour

Not reported

Incidence of new pressure ulcers

Not reported

\section{Secondary outcomes}

\section{Severity of new pressure ulcers}

Not reported 
Patient-reported outcomes

Not reported

\section{Carer-reported outcomes}

Not reported

\section{Comparison 7. Comparison between different formats of education: education delivered via e- learning versus classroom education ( I trial, 18 participants)}

\section{Primary outcome}

\section{Change in healthcare professionals' knowledge}

One study (Bredesen 2016) reported the primary outcome: change in healthcare professionals' knowledge.

Bredesen 2016 evaluated changes in nurses' knowledge of pressure ulcer classification, using 40 photos of pressure ulcers representing different categories (normal skin, categories 1 to 4), a higher score indicated better knowledge. It is unclear whether education delivered via e-learning versus education delivered via the classroom makes any difference to health professionals' knowledge, as we assessed the certainty of the evidence as very low (downgraded twice for serious limitations due to high risk of attrition and selective reporting bias, and unclear risk of selection, performance, detection and other bias, and downgraded once for serious imprecision due to small sample size) see Summary of findings 6. Participants in the e-learning group correctly classified $64 \%$ of photographs (128/ $200)$, participants in the classroom education group correctly classified $69 \%$ of photographs (111/160); (RR 0.92, 95\% CI 0.80 to 1.07; 18 participants; Analysis 6.1).

Bredesen 2016 also evaluated changes in nurses' knowledge of pressure ulcer risk assessment, using the Braden pressure ulcer risk assessment tool (Bergstrom 1987). No summative scores are provided by the study authors, however, they report that there were no differences found in Braden sub scale scores between the e-learning group and the classroom group. The report provides insufficient data to further interrogate this outcome.

Change in healthcare professionals' clinical behaviour

Not reported

\section{Incidence of new pressure ulcers}

Not reported

\section{Secondary outcomes}

\section{Severity of new pressure ulcers}

Not reported

\section{Patient-reported outcomes}

Not reported

\section{Carer-reported outcomes}

Not reported 


\section{ADDITIONALSUMMARY OF F INDINGS [Explanation]}

Training, monitoring and observation compared to monitoring and observation for preventing pressure ulcers

Patient or population: staff caring for patients at risk of pressure ulcers

Settings: nursing homes

Intervention: training, monitoring and observation

Comparison: monitoring and observation

\begin{tabular}{|c|c|c|c|c|c|c|}
\hline \multirow[t]{3}{*}{ Outcomes } & \multicolumn{2}{|c|}{ Illustrative comparative risks* $(95 \% \mathrm{Cl})$} & \multirow{3}{*}{$\begin{array}{l}\text { Relative effect } \\
(95 \% \mathrm{Cl})\end{array}$} & \multirow{3}{*}{$\begin{array}{l}\text { No of participants } \\
\text { (studies) }\end{array}$} & \multirow{3}{*}{$\begin{array}{l}\text { Quality of the evidence } \\
\text { (GRADE) }\end{array}$} & \multirow[t]{3}{*}{ Comments } \\
\hline & \multicolumn{2}{|r|}{ Corresponding risk } & & & & \\
\hline & $\begin{array}{l}\text { Monitoring and obser- } \\
\text { vation }\end{array}$ & $\begin{array}{l}\text { Training, monitoring } \\
\text { and observation }\end{array}$ & & & & \\
\hline $\begin{array}{l}\text { Change in health pro- } \\
\text { fessionals' knowledge }\end{array}$ & Not reported & & & & & \\
\hline $\begin{array}{l}\text { Change in health pro- } \\
\text { fessionals' clinical be- } \\
\text { haviour }\end{array}$ & Not reported & & & & & \\
\hline \multirow{2}{*}{$\begin{array}{l}\text { Incidence of new pres- } \\
\text { sure ulcers }\end{array}$} & Study population & & \multirow{2}{*}{$\begin{array}{l}\text { RR } 0.63 \\
(0.37 \text { to } 1.05)\end{array}$} & \multirow{2}{*}{$\begin{array}{l}345 \\
\text { (1 study) }\end{array}$} & \multirow{2}{*}{$\begin{array}{l}\oplus \bigcirc \bigcirc \bigcirc \\
\text { very low }\end{array}$} & \multirow{2}{*}{$\begin{array}{l}\text { It is uncertain whether } \\
\text { there is a difference } \\
\text { in pressure ulcer in- } \\
\text { cidence when using } \\
\text { different components } \\
\text { of educational interven- } \\
\text { tion such as training, } \\
\text { monitoring and obser- } \\
\text { vation compared with } \\
\text { monitoring and obser- } \\
\text { vation }\end{array}$} \\
\hline & 183 per 1000 & $\begin{array}{l}115 \text { per } 1000 \\
(68 \text { to } 192)\end{array}$ & & & & \\
\hline
\end{tabular}

Severity of new pres- No data were presented by the study author 
Patient-reported out- Insufficient data within the study report to further interrogate this outcome comes

Carer-reported Insufficient data within the study report to further interrogate this outcome outcomes

*The basis for the assumed risk (e.g. the median control group risk across studies) is provided in footnotes. The corresponding risk (and its $95 \%$ confidence interval) is based on the mean risk in the comparison group and the relative effect of the intervention (and its $95 \% \mathrm{Cl}$ ).

Cl: confidence interval; RR: risk ratio

GRADE Working Group grades of evidence

High quality: we are very confident that the true effect lies close to that of the estimate of the effect

Moderate quality: we are moderately confident in the effect estimate; the true effect is likely to be close to the estimate of effect, but there is a possibility that it is substantially different

Low quality: we are moderately confident in the effect estimate; the true effect is likely to be close to the estimate of effect, but there is a possibility that it is substantially different

Very low quality: we have very little confidence in the effect estimate; the true effect is likely to be substantially different from the estimate of effect

Downgraded three times: very serious limitations due to performance, detection and reporting bias; serious imprecision due

to wide confidence interval. 
Training, monitoring and observation compared to observation alone for preventing pressure ulcers

Patient or population: staff caring for patients at risk of pressure ulcers

Settings: nursing homes

Intervention: training, monitoring and observation

Comparison: observation alone

\begin{tabular}{|c|c|c|c|c|c|c|}
\hline \multirow[t]{3}{*}{ Outcomes } & \multicolumn{2}{|c|}{ Illustrative comparative risks ${ }^{*}(95 \% \mathrm{Cl})$} & \multirow{3}{*}{$\begin{array}{l}\text { Relative effect } \\
(95 \% \mathrm{Cl})\end{array}$} & \multirow{3}{*}{$\begin{array}{l}\text { No of participants } \\
\text { (studies) }\end{array}$} & \multirow{3}{*}{$\begin{array}{l}\text { Quality of the evidence } \\
\text { (GRADE) }\end{array}$} & \multirow[t]{3}{*}{ Comments } \\
\hline & \multirow{2}{*}{$\begin{array}{l}\text { Assumed risk } \\
\text { Observation alone }\end{array}$} & Corresponding risk & & & & \\
\hline & & $\begin{array}{l}\text { Training monitoring } \\
\text { and observation }\end{array}$ & & & & \\
\hline $\begin{array}{l}\text { Change in health pro- } \\
\text { fessionals' knowledge }\end{array}$ & Not reported & & & & & \\
\hline $\begin{array}{l}\text { Change in health pro- } \\
\text { fessionals' clinical be- } \\
\text { haviour }\end{array}$ & Not reported & & & & & \\
\hline \multirow{2}{*}{$\begin{array}{l}\text { Incidence of new pres- } \\
\text { sure ulcers }\end{array}$} & Study population & & \multirow{2}{*}{$\begin{array}{l}\text { RR } 1.21 \\
\text { (0.6 to } 2.43 \text { ) }\end{array}$} & \multirow{2}{*}{$\begin{array}{l}325 \\
\text { (1 study) }\end{array}$} & \multirow{2}{*}{$\begin{array}{l}\oplus \bigcirc \bigcirc \bigcirc \\
\text { very low }\end{array}$} & \multirow{2}{*}{$\begin{array}{l}\text { It is uncertain whether } \\
\text { there is a difference } \\
\text { in pressure ulcer in- } \\
\text { cidence when using } \\
\text { different components } \\
\text { of educational interven- } \\
\text { tion such as training, } \\
\text { monitoring and obser- } \\
\text { vation compared with } \\
\text { observation alone }\end{array}$} \\
\hline & 94 per 1000 & $\begin{array}{l}114 \text { per } 1000 \\
(57 \text { to } 229)\end{array}$ & & & & \\
\hline
\end{tabular}


Patient-reported out- Insufficient data within the study report to further interrogate this outcome comes

Carer-reported Insufficient data within the study report to further interrogate this outcome outcomes

*The basis for the assumed risk (e.g. the median control group risk across studies) is provided in footnotes. The corresponding risk (and its $95 \%$ confidence interval) is based on the mean risk in the comparison group and the relative effect of the intervention (and its $95 \% \mathrm{Cl}$ ).

Cl: confidence interval; RR: risk ratio

GRADE Working Group grades of evidence

High quality: we are very confident that the true effect lies close to that of the estimate of the effect

Moderate quality: we are moderately confident in the effect estimate; the true effect is likely to be close to the estimate of effect, but there is a possibility that it is substantially different

Low quality: we are moderately confident in the effect estimate; the true effect is likely to be close to the estimate of effect, but there is a possibility that it is substantially different

Very low quality: we have very little confidence in the effect estimate; the true effect is likely to be substantially different from the estimate of effect

Downgraded three times: very serious limitations due to performance, detection and reporting bias; serious imprecision due

to wide confidence interval. 
Monitoring and observation compared to observation alone for preventing pressure ulcers

Patient or population: staff caring for patients at risk of pressure ulcers

Settings: nursing homes

Intervention: monitoring and observation

Comparison: observation alone

\begin{tabular}{|c|c|c|c|c|c|c|}
\hline \multirow[t]{3}{*}{ Outcomes } & \multicolumn{2}{|c|}{ Illustrative comparative risks ${ }^{*}(95 \% \mathrm{Cl})$} & \multirow{3}{*}{$\begin{array}{l}\text { Relative effect } \\
(95 \% \mathrm{Cl})\end{array}$} & \multirow{3}{*}{$\begin{array}{l}\text { No of participants } \\
\text { (studies) }\end{array}$} & \multirow{3}{*}{$\begin{array}{l}\text { Quality of the evidence } \\
\text { (GRADE) }\end{array}$} & \multirow{3}{*}{ Comments } \\
\hline & Assumed risk & Corresponding risk & & & & \\
\hline & Observation alone & $\begin{array}{l}\text { Monitoring and obser- } \\
\text { vation }\end{array}$ & & & & \\
\hline $\begin{array}{l}\text { Change in health pro- } \\
\text { fessionals' knowledge }\end{array}$ & Not reported & & & & & \\
\hline $\begin{array}{l}\text { Change in health pro- } \\
\text { fessionals' clinical be- } \\
\text { haviour }\end{array}$ & Not reported & & & & & \\
\hline \multirow[t]{2}{*}{$\begin{array}{l}\text { Incidence of new pres- } \\
\text { sure ulcers }\end{array}$} & Study population & & \multirow[t]{2}{*}{$\begin{array}{l}\text { RR } 1.93 \\
\text { (0.96 to } 3.88)\end{array}$} & \multirow[t]{2}{*}{$\begin{array}{l}232 \\
\text { (1 study) }\end{array}$} & \multirow[t]{2}{*}{$\begin{array}{l}\oplus \bigcirc \bigcirc \bigcirc \\
\text { very low }\end{array}$} & \multirow{2}{*}{$\begin{array}{l}\text { It is uncertain whether } \\
\text { there is a difference } \\
\text { in pressure ulcer in } \\
\text { cidence when using } \\
\text { different components } \\
\text { of educational interven } \\
\text { tion such as monitoring } \\
\text { and observation com- } \\
\text { pared with observation } \\
\text { alone }\end{array}$} \\
\hline & 94 per 1000 & $\begin{array}{l}182 \text { per } 1000 \\
\text { (91 to } 366)\end{array}$ & & & & \\
\hline
\end{tabular}

Severity of new pres- No data are presented by the study author

sure ulcers 
Patient reported out- Insufficient data within the study report to further interrogate this outcome comes

Carer reported out- Insufficient data within the study report to further interrogate this outcome comes

*The basis for the assumed risk (e.g. the median control group risk across studies) is provided in footnotes. The corresponding risk (and its $95 \%$ confidence interval) is based on the mean risk in the comparison group and the relative effect of the intervention (and its $95 \% \mathrm{Cl}$ ).

Cl: confidence interval; RR: risk ratio

GRADE Working Group grades of evidence

High quality: we are very confident that the true effect lies close to that of the estimate of the effect

Moderate quality: we are moderately confident in the effect estimate; the true effect is likely to be close to the estimate of effect, but there is a possibility that it is substantially different

Low quality: we are moderately confident in the effect estimate; the true effect is likely to be close to the estimate of effect, but there is a possibility that it is substantially different

Very low quality: we have very little confidence in the effect estimate; the true effect is likely to be substantially different from the estimate of effect

'Downgraded three times: very serious limitation due to performance, detection and reporting bias; serious imprecision due

to wide confidence interval. 


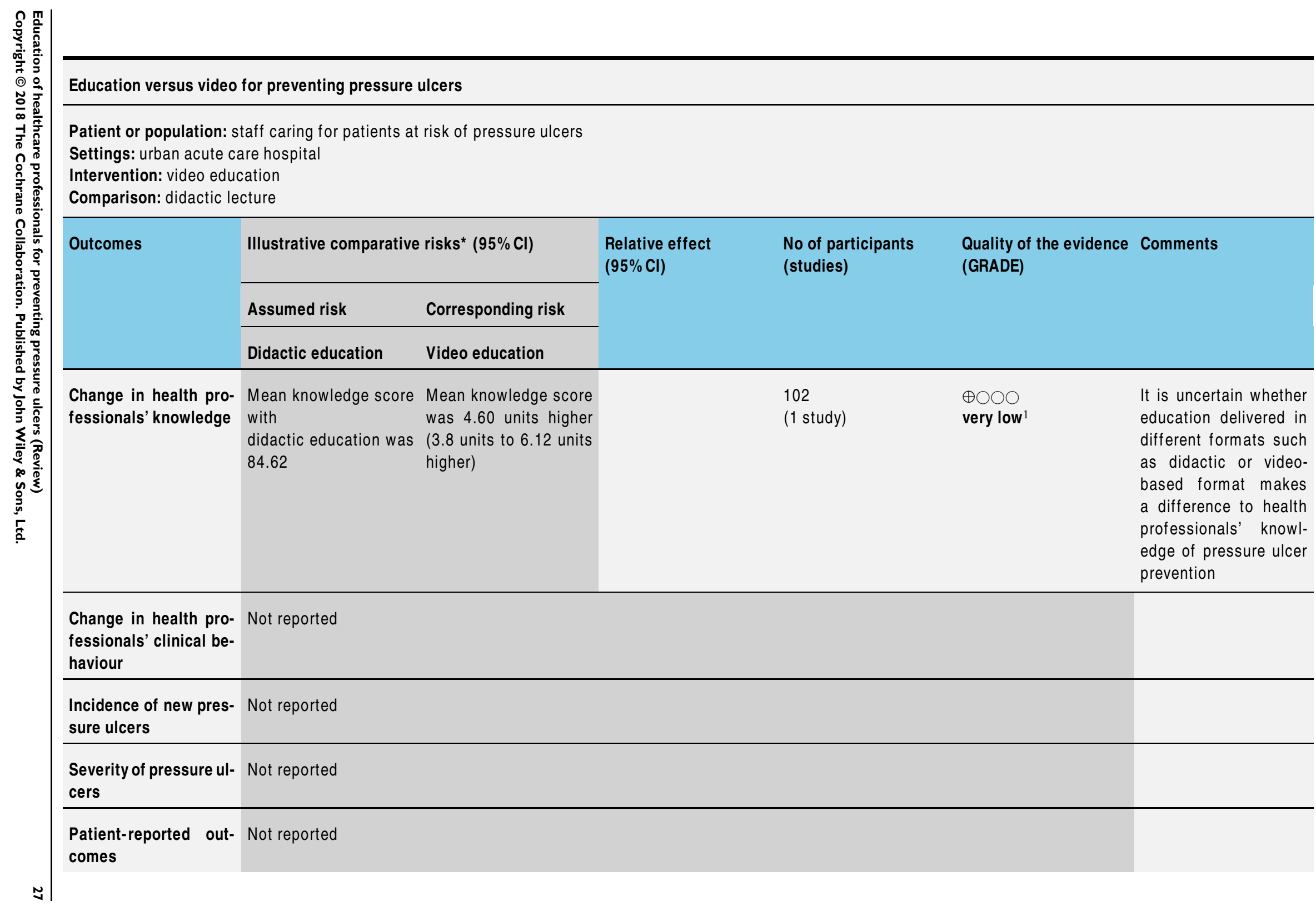




\section{Carer-reported Not reported}

outcomes

*The basis for the assumed risk (e.g. the median control group risk across studies) is provided in footnotes. The corresponding risk (and its $95 \%$ confidence interval) is based on the mean risk in the comparison group and the relative effect of the intervention (and its $95 \% \mathrm{Cl}$ ).

Cl: Confidence interval;

GRADE Working Group grades of evidence

High quality: we are very confident that the true effect lies close to that of the estimate of the effect

Moderate quality: we are moderately confident in the effect estimate; the true effect is likely to be close to the estimate of effect, but there is a possibility that it is substantially different

Low quality: we are moderately confident in the effect estimate; the true effect is likely to be close to the estimate of effect, but there is a possibility that it is substantially different

Very low quality: we have very little confidence in the effect estimate; the true effect is likely to be substantially different from the estimate of effect

${ }^{1}$ Downgraded three times: serious limitation due to unclear risk of selection, performance and detection bias; very serious imprecision due to small sample size and wide confidence intervals. 
E-learning compared with classroom education for preventing pressure ulcers

Patient or population: staff caring for patients at risk of pressure ulcers

Settings: hospitals and nursing homes

Intervention: e-learning

Comparison: classroom education

\begin{tabular}{|c|c|c|c|c|c|c|}
\hline \multirow[t]{3}{*}{ Outcomes } & \multicolumn{2}{|c|}{ Illustrative comparative risks* $(95 \% \mathrm{Cl})$} & \multirow{3}{*}{$\begin{array}{l}\text { Relative effect } \\
(95 \% \mathrm{Cl})\end{array}$} & \multirow{3}{*}{$\begin{array}{l}\text { No of participants } \\
\text { (studies) }\end{array}$} & \multirow{3}{*}{$\begin{array}{l}\text { Quality of the evidence } \\
\text { (GRADE) }\end{array}$} & \multirow[t]{3}{*}{ Comments } \\
\hline & Assumed risk & Corresponding risk & & & & \\
\hline & Classroom education & E-learning & & & & \\
\hline \multirow{2}{*}{$\begin{array}{l}\text { Knowledge of pressure } \\
\text { ulcer } \\
\text { classification }\end{array}$} & Study population & & \multirow[t]{2}{*}{ RR 0.92 (0.80 to 1.07$)$} & \multirow{2}{*}{$\begin{array}{l}18 \text { participants } \\
\text { ( } 1 \text { study) }\end{array}$} & \multirow{2}{*}{$\begin{array}{l}\text { very low }{ }^{1} \\
\oplus \bigcirc \bigcirc \bigcirc\end{array}$} & \multirow{2}{*}{$\begin{array}{l}\text { It is uncertain whether } \\
\text { education delivered in } \\
\text { different formats such } \\
\text { as e-learning or class- } \\
\text { room-based for } \\
\text { mat makes a difference } \\
\text { to health professionals } \\
\text { knowledge of pressure } \\
\text { ulcer prevention }\end{array}$} \\
\hline & 694 per 1000 & $\begin{array}{l}638 \text { per } 1000 \\
(555 \text { to } 742)\end{array}$ & & & & \\
\hline
\end{tabular}

Change in health pro- Not reported

fessionals' clinical be-

haviour

Incidence of new pres- Not reported

sure ulcers

Severity of pressure ul- Not reported

cers

Patient-reported out- Not reported

comes 


\section{Carer-reported Not reported}

outcomes

* The basis for the assumed risk (e.g. the median control group risk across studies) is provided in footnotes. The corresponding risk (and its $95 \%$ confidence interval) is based on the mean risk in the comparison group and the relative effect of the intervention (and its $95 \% \mathrm{Cl}$ ).

Cl: confidence interval; RR: risk ratio

GRADE Working Group grades of evidence

High quality: we are very confident that the true effect lies close to that of the estimate of the effect

Moderate quality: we are moderately confident in the effect estimate; the true effect is likely to be close to the estimate of effect, but there is a possibility that it is substantially different

Low quality: we are moderately confident in the effect estimate; the true effect is likely to be close to the estimate of effect, but there is a possibility that it is substantially different

Very low quality: we have very little confidence in the effect estimate; the true effect is likely to be substantially different from the estimate of effect

${ }^{1}$ Downgraded three times: serious limitations due to high risk of attrition and selective reporting bias; unclear risk of performance, selection, detection and other bias; serious imprecision due to small sample size and wide confidence intervals. 


\section{DISCUSSION}

\section{Summary of main results}

We identified five studies that met the inclusion criteria for this review (Bredesen 2016; Hayes 1994; James 1998; Rantz 2012; Van Gaal 2010). Due to the heterogeneity of the studies identified, pooling was not appropriate and we presented a narrative overview. We explored three key comparisons (1) education versus no education (2) components of educational intervention in a number of combinations and (3) education delivered in different formats.

We are uncertain whether there is a difference in health professionals' knowledge depending on whether they receive education or no education on pressure ulcer prevention. This was based on very low-certainty evidence from one study, Van Gaal 2010. We downgraded the evidence for serious study limitations, indirectness, and imprecision.

We are uncertain whether there is a difference in pressure ulcer incidence when using different components of educational interventions such as combinations of training, monitoring and observation or multilevel interventions versus control. This is based upon very low-certainty evidence from two studies (James 1998; Rantz 2012). We downgraded the evidence for serious study limitations and study imprecision.

We are uncertain whether education delivered in different formats such as didactic education and video-based education or e-learning and classroom education, makes any difference to health professionals' knowledge of pressure ulcer prevention. This is based upon very low-certainty evidence from two studies (Bredesen 2016; Hayes 1994). We downgraded the evidence for serious study limitations and study imprecision.

No studies explored our other primary outcome of interest, changes in health professionals' clinical behaviour.

Only one study (James 1998) explored the secondary outcomes of interest, namely; pressure ulcer severity, patient-reported quality of life and carer-reported functional dependency level. However, the study provided insufficient information to enable our independent assessment of these outcomes within the review.

Overall these findings reflect the sparseness of the evidence base that exists in this area, and the uncertainty of the existing evidence. In summary, we are unable to determine whether educating healthcare professionals about pressure ulcer prevention makes any difference to pressure ulcer incidence, or to nurses' knowledge of pressure ulcer prevention, or healthcare professionals' clinical behaviour. This is because the studies we included were at unclear, or high risk of bias and GRADE assessment determined that all studies provided very low-certainty evidence. Therefore, further information is required to clarify the impact of education of healthcare professionals on the prevention of pressure ulcers.

\section{Overall completeness and applicability of}

\section{evidence}

Delivery of education to healthcare professionals to prevent pressure ulcers has only been evaluated in five, small, randomised or cluster-randomised controlled trials. This resulted in very limited evidence. We were unable to undertake any meta-analyses or subgroup analyses due to the heterogeneity of the included studies. All five studies investigated a different healthcare setting, from nursing homes (Rantz 2012) and residential homes (James 1998) to hospital-based wards (Van Gaal 2010) and staff (Bredesen 2016; Hayes 1994). None of the studies used the same outcome measures to assess efficacy. All five studies delivered different formats and educational content. This wide variation in setting, outcome assessment, format and content led to ineligibility of direct comparisons. None of the five studies delivered education to staff from outside a nursing background or nursing role.

The incongruity between targeting an intervention at healthcare staff and measuring outcomes and anticipating changes at patient level (pressure ulcer incidence) must be acknowledged. In addition, in some of the trials, patients were included in the trials regardless of their risk of pressure ulceration. This could explain small or absent effects, as those without risk are not going to benefit from this intervention. One way to address this would be to recruit individuals 'at risk' and then monitor whether the educational intervention changed the risk of developing pressure ulcers. To design appropriately powered studies to explore the effects of healthcare interventions directly on pressure ulcer incidence would require very large clinical populations, potentially resulting in unfeasible and non-pragmatic trials. Thus, pressure ulcer studies such as those contained within this review select interim or proxy outcomes that may represent a precursor to the development of new pressure ulcers, or provide evidence to support preventative practices in the area, or both.

A further layer of disassociation between the intervention at staff level and the real outcome of interest (pressure ulcer incidence) occurs due to the use of the cluster-RCT design adopted by one of the five studies in this review. This study randomised groups of healthcare staff based upon the care setting in which the healthcare staff were employed. The care recipients were, by default, recruited to participate in the study by virtue of their care placement and not primarily upon their 'risk' of developing a pressure ulcer. Thus measuring for any intervention effect at patient level using this design is further obscured.

\section{Quality of the evidence}

Overall, the evidence was assessed as being of very low certainty for the key outcomes of pressure ulcer incidence and healthcare professionals' knowledge.

Given the heterogeneity of the study outcomes and the inability to pool data, we applied the GRADE criteria to each study individually, as opposed to a combined body of evidence pertaining to key outcomes. Further, we were only able to partially apply the 
GRADE criteria listed in the methods section; of the five key criteria listed, we could not assess the evidence for inconsistency or for publication bias due to the absence of meta-analysis and the very small number of studies reviewed $(n=5)$. However, we did apply the GRADE criteria against the issues of study limitations, indirectness and imprecision (see Summary of findings for the main comparison; Summary of findings 2; Summary of findings 3; Summary of findings 4; Summary of findings 5; Summary of findings 6). The most serious limitation and reason for downgrading the certainty of the evidence across all five studies was risk of bias and study imprecision. Further research is therefore very likely to have an important impact on the confidence of the estimates of effect for these measured outcomes.

Issues such as poor reporting of randomisation methods, absence of allocation concealment and blinded outcome assessment, the lack of intention-to-treat analysis, attrition and small sample sizes means that there is no strong evidence upon which to base our knowledge and practices in this area. High-quality RCTs, with sample sizes of sufficient power to detect clinically important differences between groups with improved methodology and reporting, and a more standardised content and format of delivery involving a multi-disciplinary healthcare staff are required. This type of evidence to underpin the education of healthcare professionals to prevent pressure ulcers will help to direct effective programmes that will ultimately enhance patient care in this area.

\section{Potential biases in the review process}

This review considered all the evidence that met the review criteria. We were only able to access the study by James 1998 from the study authors in original, full-report form. The report contained limited data on the secondary outcomes of interest, however, data were available for the primary outcome and we included them in the review.

\section{Agreements and disagreements with other studies or reviews}

There are no other systematic reviews of RCTs relating to education of healthcare professionals to prevent pressure ulcers. All the available RCTs to date have been scrutinised for this review.

\section{A U THORS, CONCLUSIONS}

\section{Implications for practice}

Education of healthcare staff is considered an integral component of pressure ulcer prevention (Dealey 2007). Findings from this review show uncertainty as to whether education of healthcare professionals makes any difference to knowledge of pressure ulcer prevention, or to pressure ulcer incidence. This is because the included studies provided very low-certainty evidence. There is also no randomised evidence relating to impact on healthcare professionals/ clinical practice. Therefore, further information is required to clarify the impact of education of healthcare professionals on the prevention of pressure ulcers in practice.

\section{Implications for research}

The evidence base for the education of healthcare staff to prevent pressure ulcers is very limited. Further high-quality, randomised controlled trials are needed to provide the evidence to underpin these preventative practices. There is a need for large, fully powered sample sizes, improved methodology and reporting using the CONSORT guidelines (Schultz 2010), and a more standardised content and format of delivery involving healthcare staff.

\section{ACKNOWLEDGEMENTS}

The authors would like to acknowledge the assistance of the Cochrane Wounds editorial team and the contribution of peer reviewers Sonya Osborne, Giovanni Casazza, Damian Francis, Victoria Steelman, Ajima Olaghere and Ruth Ropper for their comments on the protocol; and of Andrea Nelson, Zipporah IheozorEjiofor, Carolina Weller and Janet Gunderson for their feedback on the review. Thanks are also due to copy-editors Clare Dooley and Denise Mitchell.

\section{REF E R E N C E S}

\section{References to studies included in this review}

Bredesen 2016 \{published data only\}

Bredesen IM, Bjoro K, Gunningberg L, Hofoss D. Effect of e-learning program on risk assessment and pressure ulcer classification - a randomized study. Nurse Education Today 2016;40:191-7.

Hayes 1994 \{published data only\} Hayes PA, Wolf ZR, McHugh MK. Effect of a teaching plan on a nursing staff's knowledge of pressure ulcer risk, assessment and treatment. Journal of Nursing Staff Development 1994;10(4):207-13.

James 1998 \{published data only\} James G, Nicholl J, Slack R, McCabe C, Pirie P, McClemont E. Setting Targets: Achieving Reductions in Pressure Sores. Final Report to the DoH. Sheffield, UK: Medical Care Research Unit (MCRU), University of Sheffield, 1998. 
Rantz 2012 \{published data only\}

Rantz MJ, Zwygart-Stauffacher M, Hicks L, Mehr D, Flesner M, Petroski GF, et al. Randomized multilevel intervention to improve outcomes of residents in nursing homes in need of improvement. JAMDA 2012;13(1):60-8.

Van Gaal 2010 \{published data only\}

Van Gaal BG, Schoonhoven L, Vloet LC, Mintjes JA, Borm GF, Koopmans RT, et al. The effect of the SAFE or SORRY? programme on patient safety knowledge of nurses in hospitals and nursing homes: a cluster randomised trial. International Journal of Nursing Studies 2010;47:1117-25.

\section{References to studies excluded from this review}

Danchaivijitr 1995 \{published data only\}

Danchaivijitr S, Suthisanon L, Jitreecheue L, Tantiwatanapaibool Y. Effects of education on the prevention of pressure sores. Journal of the Medical Association of Thailand 1995;78(1):1-6.

Esche 2015 \{published data only\}

Esche CA, Warren JI, Woods AB, Jesada EC, Iliuta R. Traditional classroom education versus computer based learning: how nurses learn about pressure ulcers. Journal for Nurses in Professional Development 2015;31(1):21-7.

Rantz 2001 \{published data only\}

Rantz MJ, Popejoy L, Petroski GF, Madsen RW, Mehr DR, Zwygart-Stauffacher M, et al. Randomized clinical trial of a quality improvement intervention in nursing homes. Gerontologist 2001;41:525-38.

Shannon 2012 \{published data only\}

Shannon RJ, Brown L, Chakravarthy D. Pressure ulcer prevention program study: a randomized, controlled prospective comparative value evaluation of 2 pressure ulcer prevention strategies in nursing and rehabilitation centers. Advances in Skin and Wound Care 2012;25(10):450-64.

\section{References to ongoing studies}

\section{IRCT2017080935602N1 \{published data only\}}

IRCT2017080935602N1. The effect of pressure ulcer management educational program on the performance of nurses in the care of patients admitted to the intensive care unit. en.irct.ir/trial/26861 (first received 19 October 2017).

\section{NCT02270385 \{published data only\}}

NCT02270385. The effectiveness of a pressure ulcer prevention programme for older people in for-profit private nursing homes. clinicaltrials.gov/ct2/show/NCT02270385 (first received 21 October 2014).

\section{Additional references}

\section{Agreda 2007}

Agreda JJ, Ibou JE, Posnett J, Soriano JV, San Miguel L, Santos JM. An approach to the economic impact of the treatment of pressure ulcers in Spain. Gerokomos 2007;18 (4):201-10

\section{Anderson 2008}

Anderson ES, Karlsmark T. Evaluation of four non-invasive methods for examination and characterization of pressure ulcers. Skin Research and Technology 2008;14(3):270-6.

\section{Bates-Jensen 2009}

Bates-Jensen BM, Guihan M, Garber SL, Chin AS, Burns SP. Characteristics of recurrent pressure ulcers in veterans with spinal cord injury. Journal of Spinal Cord Medicine 2009;31(1):34.

\section{Beeckman 2008}

Beeckman D, Schoonhoven L, Boucque H, Van Maele G, Defloor T. Pressure ulcers: e-learning to improve classification by nurses and nursing students. Journal of Clinical Nursing 2008;17(13):1697-707.

Bennett 2004

Bennett G, Dealey C, Posnett J. The cost of pressure ulcers in the UK. Age and Ageing 2004;33(3):230-5.

\section{Bergstrom 1987}

Bergstrom N, Braden BJ, Laguzza A, Holman V. The Braden Scale for predicting pressure sore risk. Nursing Research 1987;36(4):205-10.

Brem 2010

Brem H, Maggi J, Nierman D, Rolnitzky L, Bell D, Rennert $\mathrm{R}$, et al. High cost of stage IV pressure ulcers. American Journal of Surgery 2010;20(4):473-7.

Byrne 1996

Byrne DW, Salzberg CA. Major risk factors for pressure ulcers in the spinal cord disabled: a literature review. Spinal Cord 1996;34(5):255-63.

\section{Coleman 2014}

Coleman S, Nixon J, Keen J, Wilson L, McGinnis E, Dealey C, et al. Discussion paper: a new pressure ulcer conceptual framework. Journal of Advanced Nursing 2014; 70(10):2222-34.

\section{David 1983}

David JA, Chapman RG, Chapman EJ. An Investigation of the Current Methods Used in Nursing for the Care of Patients with Established Pressure Sores. Harrow: Nursing Practice Research Unit, 1983.

Dealey 2007

Dealey C. Managing Pressure Sore Prevention. Salisbury, Wiltshire: Quay Books, 2007.

Demarre 2011

Demarre L, Vanderwee K, Defloor T, Verhaeghe $S$, Schoonhoven L, Beeckman D. Pressure ulcers: knowledge and attitude of nurses and nursing assistants in Belgian nursing homes. Journal of Clinical Nursing 2011;21(9-10): $1425-34$.

\section{DoH 2009}

UK Department of Health (DoH). NHS 2010-2015 from good to great: preventative, people-centred, productive. www.gov.uk/government/uploads/system/ uploads/attachment_data/file/228885/7775.pdf (accessed 11 January 2018) 


\section{Elliott 2008}

Elliott R, McKinley S, Fox V. Quality improvement program to reduce the prevalence of pressure ulcers in an intensive care unit. American Journal of Critical Care 2008; 17(4):328-34.

\section{EPOC 2018}

Cochrane Effective Practice and Organisation of Care (EPOC) Group. EPOC resources for review authors. epoc.cochrane.org/epoc-specific-resources-review-authors (accessed 11 January 2018).

\section{Gefen 2008}

Gefen A, Van Nierop B, Bader DL, Oomens CJ. Straintime cell-death threshold for skeletal muscle in a tissueengineered model system for deep tissue injury. Journal of Biomechanics 2008;41(9):2003-12.

\section{Gethin 2005}

Gethin G, Jordan-O’Brien J, Moore Z. Estimating costs of pressure area management based on a survey of ulcer care in one Irish hospital. Journal of Wound Care 2005;14(4): $162-5$.

\section{Graves 2005}

Graves N, Birrell F, Whitby M. The effect of pressure ulcers on length of hospital stay. Infection Control and Hospital Epidemiology 2005;26(3):293-7.

\section{Gunningberg 2008}

Gunningberg L, Stotts NA. Tracking quality over time: what do pressure ulcer data show?. International Journal for Quality in Health Care 2008;20(4):246-53.

\section{Guyatt 2011}

Guyatt GH, Oxman AD, Schunemann HJ, Tugwell P, Knottnerus A. GRADE guidelines: a new series of articles in the Journal of Clinical Epidemiology. Journal of Clinical Epidemiology 2011;64(4):380-2.

\section{Higgins 2011a}

Higgins JP, Altman DG, Sterne JA. Chapter 8: Assessing risk of bias in included studies. In: Higgins JP, Green $S$, editor(s). Cochrane Handbook for Systematic Reviews of Interventions Version 5.1.0 (updated March 2011). The Cochrane Collaboration, 2011. Available from handbook.cochrane.org.

Higgins 2011b

Higgins JP, Deeks JJ. Chapter 7: Selecting and collecting data. Higgins JP, Green S, editor(s). Cochrane Handbook for Systematic Reviews of Interventions Version 5.1.0 (updated March 2011). The Cochrane Collaboration, 2011. Available from handbook.cochrane.org.

\section{HIS 2011}

Healthcare Improvement Scotland (HIS). SSKIN care bundle. www.healthcareimprovementscotland.org/ our_work/patient_safety/tissue_viability/ sskin_care_bundle.aspx (accessed 11 January 2018).

\section{Kaltenthaler 2001}

Kaltenthaler E, Withfield MD, Walters SJ, Akehurst RL, Paisley S. UK, USA and Canada: how do pressure ulcer prevalence and incidence data compare?. Journal of Wound Care 2001;10(1):530-5.

\section{Kwong 2011}

Kwong EW, Lau AT, Lee RL, Kwan RY. A pressure ulcer prevention programme specially designed for nursing homes: does it work?. Journal of Clinical Nursing 2011;20 (19-20):2777-86

\section{Lefebvre 2011}

Lefebvre C, Manheimer E, Glanville J. Chapter 6: Searching for studies. In: Higgins JP, Green S, editor(s). Cochrane Handbook for Systematic Reviews of Interventions Version 5.1.0 (updated March 2011). The Cochrane Collaboration, 2011. Available from handbook.cochrane.org.

\section{Liberati 2009}

Liberati A, Altman DG, Tetzlaff J, Mulrow C, Gøtzsche PC, Ioannidis JP, et al. The PRISMA statement for reporting systematic reviews and meta-analyses of studies that evaluate health care interventions: explanation and elaboration. BMJ 2009; Vol. 339:b2700.

\section{Magnan 2008}

Magnan M, Maklebust J. Multisite web-based training in using the Braden Scale to predict pressure sore risk. Advances in Skin and Wound Care 2008;21(3):124-33.

\section{Mahoney 1965}

Mahoney FI, Barthel DW. Functional evaluation: the Barthel Index. Maryland State Medical Journal 1965;14: $61-5$.

\section{Melzack 1975}

Melzack R. The McGill Pain Questionnaire: major properties and scoring methods. Pain 1975;1(3):277-99.

\section{Moore 2011}

Moore Z, Cowman S. Pressure ulcer prevalence and prevention practices in care of the older person in the Republic of Ireland. Journal of Clinical Nursing 2011;21(34):362-71.

\section{Moore 2013}

Moore Z, Johanssen E, Van Etten M. A review of PU prevalence and incidence across Scandinavia, Iceland and Ireland (Part I). Journal of Wound Care 2013;22(7):361-2.

\section{Norton 1975}

Norton D, McClaren R, Exton-Smith AN. An Investigation of Geriatric Nursing Problems in Hospital. Edinburgh: Churchill Livingstone, 1975.

\section{NPSA 2010}

National Patient Safety Agency (NPSA). NHS to adopt zero tolerance approach to pressure ulcers. www.npsa.nhs.uk/ corporate/news/nhs-to-adopt-zero-tolerance-approach-topressure-ulcers/ (accessed 11 January 2018).

\section{NPUAP 2013}

National Pressure Ulcer Advisory Panel (NPUAP). Registered nurse competency-based curriculum: pressure ulcer prevention. Updated 2013. www.npuap.org/ resources/educational-and-clinical-resources/nursingcurriculum/ (accessed 11 January 2018). 


\section{NPUAP/EPUAP/PPPIA 2014}

National Pressure Ulcer Advisory Panel (NPUAP), European Pressure Ulcer Advisory Panel (EPUAP), Pan Pacific Pressure Injury Alliance (PPPIA). Prevention and treatment of pressure ulcers: quick reference guide. Updated 2014. www.npuap.org/wp-content/uploads/2014/ 08/Quick-Reference-Guide-DIGITAL-NPUAP-EPUAPPPPIA-Jan2016.pdf (accessed 11 January 2018).

Oemar 2013

Oemar M, Janssen B. EQ-5D-5L user guide: basic information on how to use the EQ-5D-5L instrument. www.euroqol.org (accessed 11 January 2018).

Pope 1999

Pope R. Pressure sore formation in the operating theatre: 2 . British Journal of Nursing 1999;8(5):307-12.

\section{RCN 2001}

Royal College of Nursing (RCN). Clinical practice guidelines: pressure ulcer risk assessment and prevention. Recommendations 2001. www.rcn.org.uk/_data/assets/ pdf_file/0003/78501/001252.pdf (accessed 11 January 2018).

\section{Reddy 2006}

Reddy M, Gill SS, Rochon PA. Preventing pressure ulcers: a systematic review. JAMA 2006;296(8):974-84.

Review Manager 2014 [Computer program]

Nordic Cochrane Centre, The Cochrane Collaboration. Review Manager 5 (RevMan 5). Version 5.3. Copenhagen: Nordic Cochrane Centre, The Cochrane Collaboration, 2014.

\section{Ryan 2006}

Ryan JM. Teamwork keeps the pressure off: the role of the occupational therapist in the prevention of pressure ulcers. Home Healthcare Nurse 2006;24(2):97-102.

\section{Schultz 2010}

Schulz KF, Altman DG, Moher D, for the CONSORT Group. CONSORT 2010 Statement: updated guidelines for reporting parallel group randomised trials. Annals of Internal Medicine 2010;162:Epub 24 March 2010.

\section{Schünemann 2011}

Schünemann HJ, Oxman AD, Vist GE, Higgins JP,

Deeks JJ, Glasziou P, et al. Chapter 12: Interpreting results and drawing conclusions. In: Higgins JP, Green S, editor(s). Cochrane Handbook for Systematic Reviews of Interventions Version 5.1.0 (updated March 2011). The Cochrane Collaboration, 2011. Available from handbook.cochrane.org.

\section{Shapcott 1999}

Shapcott N, Levy B. By the numbers: making the case for clinical use of pressure management mat technology to prevent the development of pressure ulcers. www.wheelchairnet.org/wcn_prodserv/Docs/TeamRehab/ RR_99/Jan_99/9901art1.pdf (accessed 11 January 2018).

\section{SIGN 2018}

Scottish Intercollegiate Guidelines Network (SIGN). Search filters. www.sign.ac.uk/search-filters.html (accessed 18 May 2018).

\section{Sterne 2010}

Sterne JA, Egger M, Moher D (editors). Chapter 10: Addressing reporting biases. In: Higgins JPT, Green $S$ (editors). Cochrane Handbook for Systematic Reviews of Interventions. Version 5.1.0 (updated March 2011). The Cochrane Collaboration, 2011. Available from handbook.cochrane.org.

\section{Stinson 2013}

Stinson M, Gillan C, Porter-Armstrong A. A literature review of pressure ulcer prevention: weight shift activity, cost of pressure care and the role of the OT. British Journal of Occupational Therapy 2013;76(4):1-10.

\section{Stroupe 2011}

Stroupe KT, Manheim L, Evans CT, Guihan M, Ho C, $\mathrm{Li} \mathrm{K}$, et al. Cost of treating pressure ulcers for veterans with spinal cord injury. Topics in Spinal Cord Injury Rehabilitation 2011;16(4):62-73.

\section{Thomas 2010}

Thomas DR. Does pressure cause pressure ulcers? An inquiry into the etiology of pressure ulcers. Journal of the American Medical Directors Association 2010;11(6): $397-405$.

\section{Thomas 2012}

Thomas A. Assessment of nursing knowledge and wound documentation following a pressure ulcer educational program in a long-term care facility: a capstone project. Wound Practice and Research 2012;20(3):142-58.

\section{Tweed 2008}

Tweed C, Tweed M. Intensive care nurses' knowledge of pressure ulcers: development of an assessment tool and effect of an educational program. American Journal of Critical Care 2008;17(4):338-46.

Vanderwee 2007

Vanderwee K, Clark M, Dealey C, Gunningberg L, Defloor T. Pressure ulcer prevalence in Europe: a pilot study. Journal of Evaluation in Clinical Practice 2007;13(2):227-35.

\section{VanGilder 2009}

VanGilder C, Amlung S, Harrison P, Meyer S. Results of the 2008-2009 international pressure ulcer prevalence ${ }^{T M}$ survey and a 3-year, acute care, unit-specific analysis. Ostomy Wound Management 2009;55(11):39-45.

\section{References to other published versions of this review}

\section{Porter-Armstrong 2015}

Porter-Armstrong AP, Moore ZE, Bradbury I, McDonough S. Education of healthcare professionals for preventing pressure ulcers. Cochrane Database of Systematic Reviews 2015, Issue 4. DOI: 10.1002/14651858.CD011620

* Indicates the major publication for the study 


\section{CHARACTERISTICS OF STUDIES}

\section{Characteristics of included studies [ordered by study ID]}

\section{Bredesen 2016}

$\begin{array}{ll}\text { Methods } & \text { Study design: 3-armed RCT } \\ \text { Ethics and informed consent: approval gained from each site, written consent obtained } \\ \text { from participants } \\ \text { Sample size calculation: no } \\ \text { ITT analysis: no }\end{array}$

Interventions

Aim: to develop and test an e-learning programme for the assessment of pressure ulcer risk and classification

Group A: independent e-learning module in a computer room using his/her own computer terminal (intervention) ( $\mathrm{n}=23$ nurses) content identical to control group

Group B: received 45-min classroom lecture delivered by an experienced nurse using power point presentation (classroom) $(\mathrm{n}=21$ nurses) content identical to intervention group

Group C: no education (control) - no other details supplied as, quote: "because of massive dropout, we excluded this group and test from the study"

Study date: May-December 2012

Outcomes

Primary outcomes: knowledge of risk assessment using Braden scale; knowledge of classification using stages 1-4, DTI and unstageable pressure ulcer categories (NPUAP)

Secondary outcomes: none specified

Time points: pre- and postintervention and 3 months' follow-up

Notes

Design was 3-arm RCT but only 2-arm RCT reported: quote: "because of massive dropout, we excluded this group and test from the study"

\section{Risk of bias}

Bias

Authors' judgement

\section{Support for judgement}

Random sequence generation (selection Unclear risk bias)

Quote: "we used block randomization with six in each block to ensure even distribution within the groups"

Comment: the method of generating the randomisation sequence was not described 


\begin{tabular}{|c|c|c|}
\hline Allocation concealment (selection bias) & Low risk & $\begin{array}{l}\text { Quote: "a study coordinator prepared the } \\
\text { randomization using closed, opaque num- } \\
\text { bered envelopes to conceal group alloca- } \\
\text { tion" }\end{array}$ \\
\hline $\begin{array}{l}\text { Blinding of participants and personnel } \\
\text { (performance bias) } \\
\text { All outcomes }\end{array}$ & Unclear risk & $\begin{array}{l}\text { Study protocol (NCT01567410 Clinical- } \\
\text { trials.gov), states that it was a single blind } \\
\text { study (participants) but no information } \\
\text { given in study report } \\
\text { Comment: not reported }\end{array}$ \\
\hline $\begin{array}{l}\text { Blinding of outcome assessment (detection } \\
\text { bias) } \\
\text { All outcomes }\end{array}$ & Unclear risk & Comment: not reported \\
\hline $\begin{array}{l}\text { Incomplete outcome data (attrition bias) } \\
\text { All outcomes }\end{array}$ & High risk & $\begin{array}{l}\text { Quote: "the dropout rate for the three- } \\
\text { month test for the total sample was } 59 \% \text {. } \\
\text { The dropout rate was high in both groups" } \\
\text { No reasons given by study authors on } \\
\text { high dropout rate across both arms; con- } \\
\text { trol group not reported upon due to high } \\
\text { dropout rate } \\
\text { Comment: high level of incomplete out- } \\
\text { come data detected }\end{array}$ \\
\hline Selective reporting (reporting bias) & High risk & $\begin{array}{l}\text { Quote: "the study protocol included a third } \\
\text { group without additional training and a test } \\
\text { six months after training, but because of } \\
\text { massive dropout, we excluded this group } \\
\text { and test from the study" } \\
\text { The study protocol (NCT } 01567410 \text { Clin- } \\
\text { icaltrials.gov), also reports a measurement } \\
\text { period of } 24 \text { weeks but these data were not } \\
\text { reported } \\
\text { Comment: high level of selective reporting }\end{array}$ \\
\hline Other bias & Unclear risk & $\begin{array}{l}\text { Quote: "we did not ask the nurses about } \\
\text { their computer knowledge and preferred } \\
\text { learning method" (p 196) } \\
\text { Comment: computer proficiency impact } \\
\text { upon e-learning method }\end{array}$ \\
\hline
\end{tabular}




\begin{tabular}{|c|c|}
\hline Methods & $\begin{array}{l}\text { Study design: 2-armed RCT } \\
\text { Ethics and informed consent: ethical approval not stated, written consent obtained from } \\
\text { participants } \\
\text { Sample size calculation: no } \\
\text { ITT analysis: yes }\end{array}$ \\
\hline Participants & $\begin{array}{l}\text { Location: } 102 \text { RNs, LPNs and nursing assistants employed within an urban, acute care } \\
\text { hospital } \\
\text { Mean age: reported whole-group only: range } 20-69 \text { years; mean } 33.3 \text { years; SD } 10.3 \\
\text { years } \\
\text { Gender: } 89.2 \% \text { F / } 10.8 \% \mathrm{M} \\
\text { Years nursing experience: reported whole group only: range } 1-35 \text { years; mean } 8.3 \text { years; } \\
\text { SD } 7.8 \text { years } \\
\text { Inclusion criteria: not specified } \\
\text { Exclusion criteria: not specified }\end{array}$ \\
\hline Interventions & $\begin{array}{l}\text { Aim: to determine the effectiveness of a teaching plan designed to increase a hospital } \\
\text { nursing staff's knowledge of pressure ulcer risk, assessment, and treatments } \\
\text { Group A: received } 40 \text {-min, instructional, didactic, teaching intervention of pressure ulcer } \\
\text { risk, assessment and treatment strategies }(\mathrm{n}=48) \\
\text { Group B: viewed } 25 \text {-min video on general aspects of skin care for hospitalised patients } \\
(\mathrm{n}=54) \\
\text { Study date: not stated }\end{array}$ \\
\hline
\end{tabular}

Outcomes

Primary outcomes: 100-item true / false knowledge score

Secondary outcomes: none measured

Time points: pre- and postintervention

Demographic details not provided by group

\section{Risk of bias}

\begin{tabular}{|c|c|c|}
\hline Bias & Authors' judgement & Support for judgement \\
\hline $\begin{array}{l}\text { Random sequence generation (selection } \\
\text { bias) }\end{array}$ & Unclear risk & $\begin{array}{l}\text { Quote: "a systematic random sample of } \\
\text { subjects" ... "subjects were recruited by let- } \\
\text { ter after random selection from a list of } \\
\text { nursing staff employees" ... "assigned ran- } \\
\text { domly to experimental or control groups" } \\
\text { Comment: the method of generating the } \\
\text { randomisation sequence was not described }\end{array}$ \\
\hline Allocation concealment (selection bias) & Unclear risk & Comment: not reported \\
\hline $\begin{array}{l}\text { Blinding of participants and personnel } \\
\text { (performance bias) } \\
\text { All outcomes }\end{array}$ & Unclear risk & $\begin{array}{l}\text { Comment: participants are unlikely to have } \\
\text { known which of the } 2 \text { interventions was the } \\
\text { 'active' intervention based upon whether } \\
\text { they watched the video or took part in the } \\
\text { didactic educational session but blinding }\end{array}$ \\
\hline
\end{tabular}


Hayes 1994 (Continued)

was not specifically addressed

\begin{tabular}{l|l|l}
\hline $\begin{array}{l}\text { Blinding of outcome assessment (detection } \\
\text { bias) } \\
\text { All outcomes }\end{array}$ & Unclear risk & Comment: not reported \\
\hline $\begin{array}{l}\text { Incomplete outcome data (attrition bias) } \\
\text { All outcomes }\end{array}$ & Low risk & $\begin{array}{l}\text { Comment: full set of outcome data pre- } \\
\text { sented for full cohort }\end{array}$ \\
\hline Selective reporting (reporting bias) & Low risk & $\begin{array}{l}\text { Comment: not apparent, all measures re- } \\
\text { ported }\end{array}$ \\
\hline Other bias & Low risk & None detected \\
\hline
\end{tabular}

James 1998

Methods

Study design: 3-group parallel-RCT with an 18-month follow-up period

Ethics and informed consent: ethical approval gained and informed consent taken

Sample size calculation: yes

ITT analysis: yes

Participants

Location: 37 residential homes of 726 residents in North Lincolnshire, UK

Mean ages: not reported

Patient information:

Group A: $0.8 \%<65$ years; $7.8 \% 65-74$ years; $91.4 \%>75$ years: $74 \%$ F / 26\% M

Group B: $0.5 \%<65$ years; $4.3 \% 65-74$ years; $95.1 \%>75$ years: $82 \%$ F / 18\% M

Group C: $1.2 \%<65$ years; $10.5 \% 65-74$ years; $88.3 \%>75$ years: $85 \%$ F / 15\% M

Inclusion criteria:

Residential homes were required to:

1. be registered for $>8$ residents;

2. have no nursing or dual-registered beds;

3. give consent for participation of the home;

4. agree to participation in the study prior to randomisation and continue irrespective of subsequent randomisation;

5. be within the geographical area of North Lincolnshire Health Authority.

Residents were required to:

1. give informed consent or provide by a relative or member of staff acting as advocate;

2. complete the research tools being used;

3. be a permanent resident of the home (i.e. not a short-term or respite resident).

Exclusion criteria: not specified

Interventions

Aim: to examine the effects of introducing a programme of training and monitoring to reduce pressure sores in residential homes

Group A: training, monitoring and observation (21 homes; 371 residents)

Group B: monitoring and observation (9 homes; 191 residents)

Group C: observation only (7 homes; 164 residents)

Training: 2-hour interactive session delivered by a district nurse, quote: "based upon the principles of pressure sore risk assessment using the Norton scale, pressure sore grading,

Education of healthcare professionals for preventing pressure ulcers (Review) 
and pressure sore prevention through management of nutrition, continence, mobility and moving and handling"

Monitoring: the district nurse, quote: "taught the principles of risk assessment and pressure sore grading only"

Observation: quote: "no instruction at all from the district nurse"

Study dates: not stated

Outcomes

Primary outcomes: risk assessment using Norton scale and grading using the David classification (grades 1-4)

Secondary outcomes: functional dependency using Barthel Index \& quality of life using Euroqol

Time points: baseline, 6,12 , and 18 months

\section{Notes}

\section{Risk of bias}

\begin{tabular}{l|l|l}
\hline Bias & Authors' judgement & Support for judgement \\
\hline $\begin{array}{l}\text { Random sequence generation (selection } \\
\text { bias) }\end{array}$ & Unclear risk & $\begin{array}{l}\text { Quote: "randomly selected" ... "randomly } \\
\text { allocated into one of three groups" } \\
\text { Comment: the method of generating the } \\
\text { randomisation sequence was not described }\end{array}$ \\
\hline Allocation concealment (selection bias) & Unclear risk & Comment: not reported \\
\hline
\end{tabular}

Blinding of participants and personnel High risk (performance bias)

All outcomes
Quote: "it was possible that staff of homes conducting self-monitoring of risk and pressure sores would reveal their study group by discussion with the research nurse or by asking advice"

Comment: not blinded

Quote: "the project therefore progressed without the blinding of research nurses to the home study group"

Comment: not blinded

bias)

All outcomes
Incomplete outcome data (attrition bias) Unclear risk

All outcomes

Selective reporting (reporting bias) High risk

Unclear risk

Comment: unable to assess fully from information presented within the report

Comment: not all outcomes reported on e. g. David classification

Other bias
Limited information provided pertaining to the nursing staff participants; potential publication bias 
Methods
Study design: 2-group parallel-RCT using repeated-measures design

Ethics and informed consent: not stated

Sample size calculation: yes

ITT analysis: yes
Participants
Location: 58 nursing homes in Missouri, USA

Inclusion criteria: nursing homes in need of improvement

Specifically, homes were required to improve resident outcomes of care as per the minimum data set (MDS) quality improvement scores above the 40th percentile on at least 3 of 4 selected resident outcome measures for 2 consecutive 6-month periods of MDS data. The 4 selected resident outcome measures were: bowel and bladder incontinence; weight loss; pressure ulcers and decline in activities of daily living

Exclusion criteria: not specified
Interventions
Aim: to test an experimental intervention focused on building organisational capacity to create and sustain improvement in quality of care and improve resident outcomes Group A: multilevel intervention targeted at 3 levels of staff: nursing home owners and administrative staff, nursing, and direct-care staff ( $n=29$ nursing homes)

Group B: attention control ( $\mathrm{n}=29$ nursing homes)

Multilevel intervention included: educational materials comprising a detailed intervention manual, quality improvement tools and two text books provided to leadership of each nursing home. Monthly on-site consultation from a research nurse of 1-4 hours duration. Nursing home owners were asked to provide consistent nursing and administrative leadership, to adopt elements of change into their management practices, and to support and encourage the use of team and group processes for (1) decision-making affecting resident care; (2) use of a quality improvement programme; (3) efforts of staff to focus on care basics including preventing skin breakdown, ambulation, nutrition, hydration, toileting, bowel and pain management

Attention control comprised: educational materials sent to the home on a monthly basis including video-taped, in-service training and reading material about ageing and physical assessment of elderly residents alongside monthly telephone support from the co-principal investigator

Study date: not stated
Bias

Random sequence generation (selection Unclear risk bias)
Authors' judgement

\section{Support for judgement}

Quote: "we first randomly assigned owners of facilities in the population of qualified facilities to either intervention or control groups. Then, we randomly contacted qualified facilities to participate and, when 
Rantz 2012 (Continued)

\begin{tabular}{|c|c|c|}
\hline & & $\begin{array}{l}\text { they agreed, assigned them to the group } \\
\text { designation based on owner. We continued } \\
\text { random assignment until the groups were } \\
\text { full" (p 61) } \\
\text { Comment: the method of generating the } \\
\text { randomisation sequence was not described }\end{array}$ \\
\hline Allocation concealment (selection bias) & Unclear risk & Comment: not reported \\
\hline $\begin{array}{l}\text { Blinding of participants and personnel } \\
\text { (performance bias) } \\
\text { All outcomes }\end{array}$ & Unclear risk & Comment: not reported \\
\hline $\begin{array}{l}\text { Blinding of outcome assessment (detection } \\
\text { bias) } \\
\text { All outcomes }\end{array}$ & Low risk & $\begin{array}{l}\text { Quote: "collected by an independent nurse } \\
\text { observer (blind to the intervention) at base- } \\
\text { line and at the end of years } 1 \text { and } 2 \text { in the } \\
\text { intervention group and end of year } 2 \text { in the } \\
\text { control group" (p 62) } \\
\text { Comment: outcome assessment blinded }\end{array}$ \\
\hline $\begin{array}{l}\text { Incomplete outcome data (attrition bias) } \\
\text { All outcomes }\end{array}$ & High risk & $\begin{array}{l}\text { Response rates were low on "Tell us about } \\
\text { your Nursing Home" survey (intervention } \\
\text { group } 71 \% \text { baseline \& } 63 \% \text { study end; } \\
\text { control group } 65 \% \text { baseline; } 53 \% \text { control) }\end{array}$ \\
\hline Selective reporting (reporting bias) & Low risk & Comment: outcomes reported on fully \\
\hline Other bias & Low risk & None detected \\
\hline
\end{tabular}

\section{Van Gaal 2010}

Methods

Study design: 2-group cluster-RCT

Ethics and informed consent: ethical approval gained, informed consent not stated Sample size calculation: no

ITT analysis: no

Participants

Interventions
Location: 20 wards from 4 hospitals and 6 nursing homes in the Netherlands Mean age: hospital ward nurses 38 years (SD 10.7 years); nursing home ward nurses 39 years (SD 10.2 years)

Gender: hospital ward nurses $89 \%$ female; nursing home ward nurses $96 \%$ female Inclusion criteria: none specified

Exclusion criteria: none specified

Aim: to investigate the effect of interactive and tailored education on the knowledge levels of nurses

Group A: educational intervention based upon the patient safety programme $(n=5$ nursing home wards and $\mathrm{n}=5$ hospital wards)

Group B: no educational intervention $(n=5$ nursing home wards and $n=5$ hospital wards) 


Education intervention: each nurse attended a small scale educational meeting lasting
approx 1.5 hours based upon guidelines for the prevention of pressure ulcers, urinary tract
infections and falls, accessed an educational CD containing theoretical information and
feedback test, and attended researcher-facilitated follow-up case discussions at ward-level
every 2-3 months. Appointment of 2 key nurses at each site to champion implementation
of intervention and avail of two, 5-hour outreach visits and periodic contact with the
researcher
Study date: September 2006-July 2008

Outcomes

Primary outcomes: 20-item knowledge test on pressure ulcers

Secondary outcomes: none measured

Time points: baseline and 1 year post-baseline
As nurses' characteristics differed between hospitals and nursing homes, the data were analysed for hospital wards and nursing home wards separately

Risk of bias

\begin{tabular}{l|l|l}
\hline Bias & Authors' judgement & Support for judgement \\
\hline $\begin{array}{l}\text { Random sequence generation (selection } \\
\text { bias) }\end{array}$ & Unclear risk & $\begin{array}{l}\text { Quote: "randomisation of the wards was } \\
\text { stratified for centre and type of ward“ } \\
\text { Comment: the method of generating the } \\
\text { randomisation sequence was not described }\end{array}$ \\
\hline $\begin{array}{l}\text { Allocation concealment (selection bias) } \\
\text { Blinding of participants and personnel } \\
\text { (performance bias) } \\
\text { All outcomes }\end{array}$ & Unclear risk & Comment: not reported \\
\hline
\end{tabular}

Blinding of outcome assessment (detection High risk bias)

All outcomes
Quote: "at each ward, one nurse was responsible for the distribution and collection of the questionnaires"

Comment: it is likely that this nurse knew group allocation

Incomplete outcome data (attrition bias) High risk All outcomes
Low response and high attrition rates noted in study Intervention group of hospital nurses' cohort $(80 \%$ response rate at baseline; $49 \%$ response rate study end)

Control group of hospital nurses' cohort ( $72 \%$ response rate at baseline; $87 \%$ response rate study end)

Intervention group of nursing ward nurses' 
Van Gaal 2010 (Continued)

\begin{tabular}{|c|c|c|}
\hline & & $\begin{array}{l}\text { cohort ( } 66 \% \text { response rate baseline; } 58 \% \\
\text { response rate study end) } \\
\text { Control group of nursing ward nurses' co- } \\
\text { hort ( } 71 \% \text { response rate baseline; } 56 \% \text { re- } \\
\text { sponse rate study end) }\end{array}$ \\
\hline Selective reporting (reporting bias) & Low risk & Comment: outcomes reported on fully \\
\hline Other bias & Unclear risk & $\begin{array}{l}\text { Comment: outcome measured using a non- } \\
\text { standardised assessment measure }\end{array}$ \\
\hline Recruitment bias (cluster trials only) & Low risk & $\begin{array}{l}\text { Quote: "all registered and licensed nurses } \\
\text { working within the } 20 \text { participating wards } \\
\text { were invited to participate in the study" } \\
. . \text { "in our study the intervention involved } \\
\text { the entire team of nurses and not individual } \\
\text { nurses on nursing wards" } \\
\text { Comment: recruitment bias unlikely to be } \\
\text { a source of bias }\end{array}$ \\
\hline Baseline imbalance (cluster trials only) & Low risk & $\begin{array}{l}\text { Quote: "prior to baseline, randomisation } \\
\text { of the wards to an intervention or control } \\
\text { group was stratified for centre and type of } \\
\text { ward" } \\
\text { Comment: potential baseline imbalance } \\
\text { accounted for through stratification of clus- } \\
\text { ters }\end{array}$ \\
\hline Loss of clusters (cluster trials only) & Low risk & $\begin{array}{l}\text { No loss of clusters at end point; risk of bias } \\
\text { arising from missing outcome data for indi- } \\
\text { viduals within clusters appraised as incom- } \\
\text { plete outcome data (attrition bias) } \\
\text { Comment: all clusters remained within the } \\
\text { trial }\end{array}$ \\
\hline Incorrect analysis (cluster trials only) & Low risk & $\begin{array}{l}\text { Quote: "the results were analysed for hos- } \\
\text { pitals and nursing homes separately" } . . . \\
\text { "we used a linear random effects model to } \\
\text { analyse the difference in the results on the } \\
\text { knowledge test between the intervention } \\
\text { and the control wards at follow-up. This } \\
\text { model was used because of the hierarchical } \\
\text { structure of the data (nurses were clustered } \\
\text { within wards) } \\
\text { Comment: statistical analysis took account } \\
\text { of clustering }\end{array}$ \\
\hline
\end{tabular}

Education of healthcare professionals for preventing pressure ulcers (Review) 
DTI: deep tissue injury; F: female; ITT: intention-to-treat; LPN: licensed practical nurse; M: male; NPUAP:National Pressure Ulcer Advisory Panel; RCT: randomised controlled trial; RN: registered nurse

\section{Characteristics of excluded studies [ordered by study ID]}

\begin{tabular}{l|l}
\hline Study & Reason for exclusion \\
\hline Danchaivijitr 1995 & Study design: not a RCT \\
\hline Esche 2015 & Study design: not a RCT \\
\hline Rantz 2001 & Study purpose: educational focus on quality improvement reporting and report interpretation \\
\hline Shannon 2012 & Study design: invalid comparison. Both cohorts received educational intervention \\
\hline
\end{tabular}

RCT: randomised controlled trial

\section{Characteristics of ongoing studies [ordered by study ID]}

\section{IRCT2017080935602N1}

Trial name or title The effect of pressure ulcer management educational program on the performance of nurses in the care of patients admitted to the intensive care unit

\begin{tabular}{l|l}
\hline Methods & 2 arm RCT \\
\hline Participants & 70 nurses working in intensive care unit \\
\hline $\begin{array}{l}\text { Interventions } \\
\text { A pressure ulcer management training programme including a learning workshop, educational leaflet and CD } \\
\text { for nurses }\end{array}$ \\
\hline Outcomes & Primary: nurses' performance. \\
\hline Starting date & Trial registration date October 2017 (IRCT2017080935602N1) apps.who.int/trialsearch \\
\hline Contact information & Estimated end date of recruitment February 2018 \\
\hline Notes &
\end{tabular}


Trial name or title ulcer prevention programme for private for-profit nursing homes

Methods Cluster-RCT

Participants 8 private, for-profit nursing homes

Interventions A comprehensive pressure ulcer prevention programme defined as including an intensive training course and a pressure ulcer protocol

Outcomes Primary: incidence and prevalence of pressure ulcers. Secondary: care staff's knowledge and skills on pressure ulcer prevention

Starting date

Trial registration date October 2014 (NCT02270385) clinicaltrials.gov

Contact information

Estimated end date December 2017

Notes

RCT: randomised controlled trial 
DATA AND ANALYSES

Comparison 1. Education versus no education

\begin{tabular}{|c|c|c|c|c|}
\hline Outcome or subgroup title & $\begin{array}{l}\text { No. of } \\
\text { studies }\end{array}$ & $\begin{array}{c}\text { No. of } \\
\text { participants }\end{array}$ & Statistical method & Effect size \\
\hline 1 Knowledge hospital group & 1 & & Mean Difference (IV, Fixed, 95\% CI) & Totals not selected \\
\hline 2 Knowledge nursing-home group & 1 & & Mean Difference (IV, Fixed, 95\% CI) & Totals not selected \\
\hline
\end{tabular}

Comparison 2. Training, monitoring and observation vs monitoring and observation

\begin{tabular}{lcccc} 
Outcome or subgroup title & $\begin{array}{c}\text { No. of } \\
\text { studies }\end{array}$ & $\begin{array}{c}\text { No. of } \\
\text { participants }\end{array}$ & Statistical method & Effect size \\
\hline 1 Pressure ulcer developed & 1 & & Risk Ratio (M-H, Fixed, 95\% CI) & Totals not selected \\
\hline
\end{tabular}

Comparison 3. Training monitoring and observation vs observation alone

\begin{tabular}{lcccc} 
Outcome or subgroup title & $\begin{array}{c}\text { No. of } \\
\text { studies }\end{array}$ & $\begin{array}{c}\text { No. of } \\
\text { participants }\end{array}$ & Statistical method & Effect size \\
\hline 1 Pressure ulcer developed & 1 & & Risk Ratio (M-H, Fixed, 95\% CI) & Totals not selected \\
\hline
\end{tabular}

Comparison 4. Monitoring and observation vs observation alone

\begin{tabular}{lcccc} 
Outcome or subgroup title & $\begin{array}{c}\text { No. of } \\
\text { studies }\end{array}$ & $\begin{array}{c}\text { No. of } \\
\text { participants }\end{array}$ & Statistical method & Effect size \\
\hline 1 Pressure ulcer developed & 1 & & Risk Ratio (M-H, Fixed, 95\% CI) & Totals not selected \\
\hline
\end{tabular}


Comparison 5. Education via didactic lecture versus video

\begin{tabular}{lcccc} 
Outcome or subgroup title & $\begin{array}{c}\text { No. of } \\
\text { studies }\end{array}$ & $\begin{array}{c}\text { No. of } \\
\text { participants }\end{array}$ & Statistical method & Effect size \\
\hline 1 Knowledge & 1 & & Mean Difference (IV, Fixed, 95\% CI) & Totals not selected \\
\hline
\end{tabular}

Comparison 6. E-learning versus classroom teaching

\begin{tabular}{|c|c|c|c|c|}
\hline Outcome or subgroup title & $\begin{array}{l}\text { No. of } \\
\text { studies }\end{array}$ & $\begin{array}{c}\text { No. of } \\
\text { participants }\end{array}$ & Statistical method & Effect size \\
\hline $\begin{array}{l}1 \text { Correct classification of pressure } \\
\text { ulcer photographs }\end{array}$ & 1 & & Risk Ratio (M-H, Fixed, 95\% CI) & Totals not selected \\
\hline
\end{tabular}

\section{Analysis I.I. Comparison I Education versus no education, Outcome I Knowledge hospital group.}

Review: Education of healthcare professionals for preventing pressure ulcers

Comparison: I Education versus no education

Outcome: I Knowledge hospital group

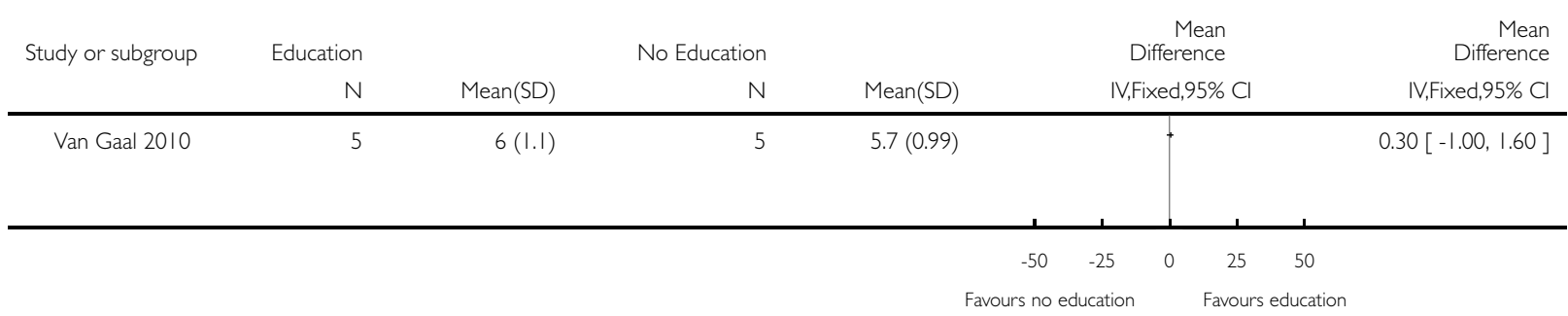


Analysis I.2. Comparison I Education versus no education, Outcome 2 Knowledge nursing-home group. Review: Education of healthcare professionals for preventing pressure ulcers

Comparison: I Education versus no education

Outcome: 2 Knowledge nursing-home group

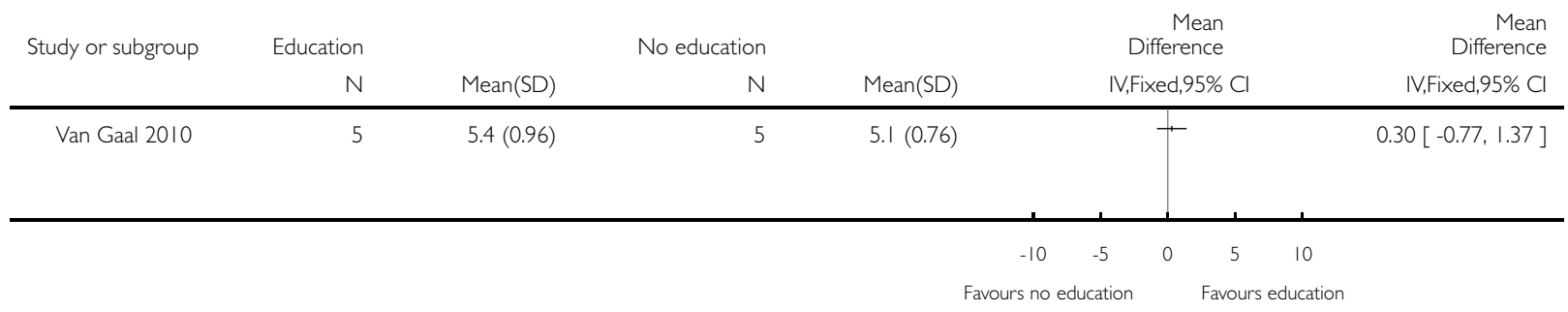

Analysis 2.I. Comparison 2 Training, monitoring and observation vs monitoring and observation, Outcome I Pressure ulcer developed.

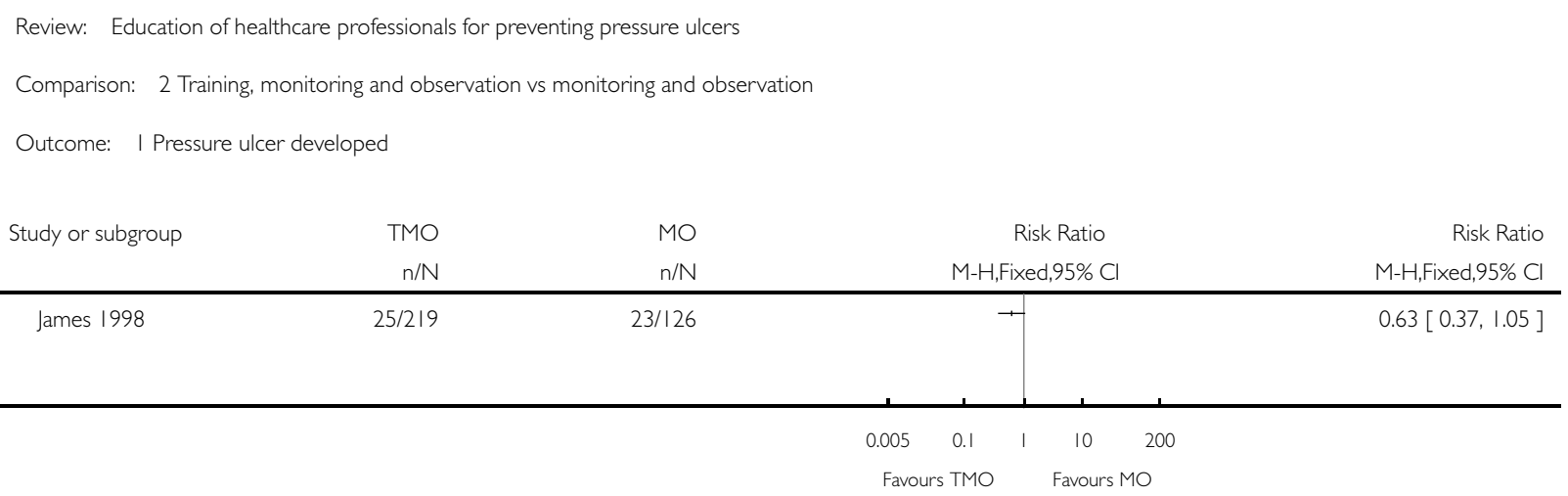




\section{Analysis 3.I. Comparison 3 Training monitoring and observation vs observation alone, Outcome I Pressure}

ulcer developed.

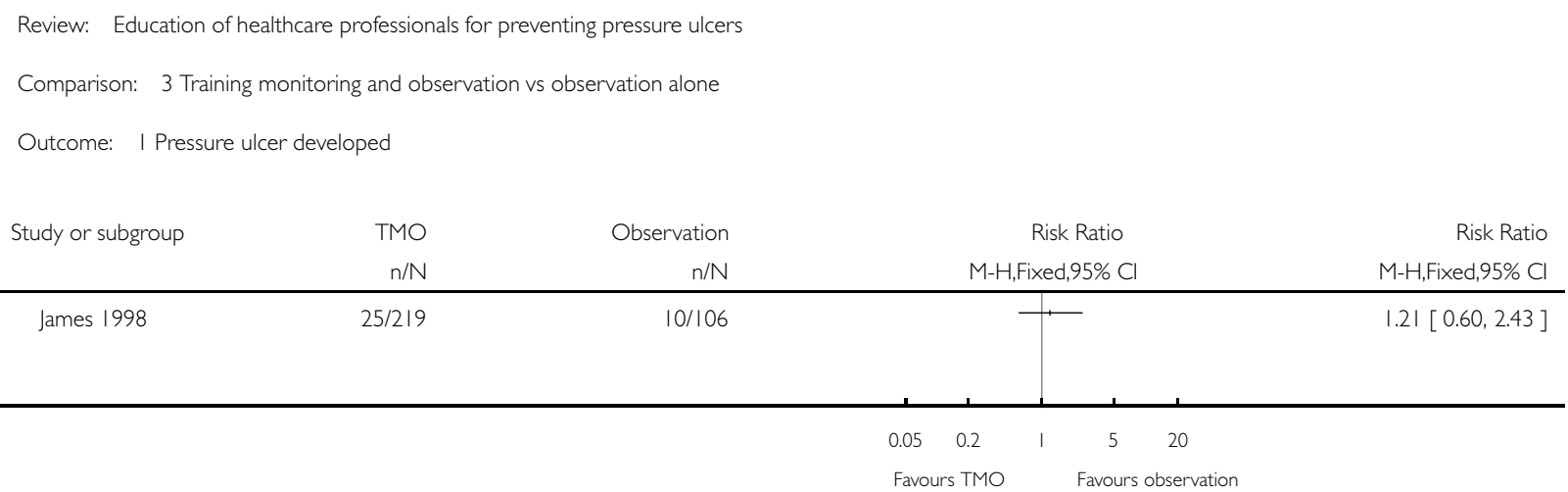

\section{Analysis 4.I. Comparison 4 Monitoring and observation vs observation alone, Outcome I Pressure ulcer} developed.

Review: Education of healthcare professionals for preventing pressure ulcers

Comparison: 4 Monitoring and observation vs observation alone

Outcome: I Pressure ulcer developed

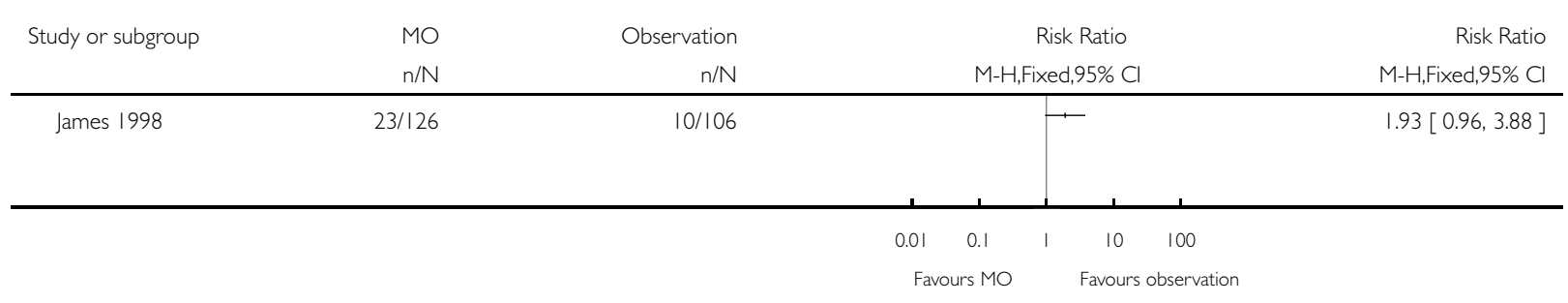




\section{Analysis 5.I. Comparison 5 Education via didactic lecture versus video, Outcome I Knowledge.}

Review: Education of healthcare professionals for preventing pressure ulcers

Comparison: 5 Education via didactic lecture versus video

Outcome: I Knowledge

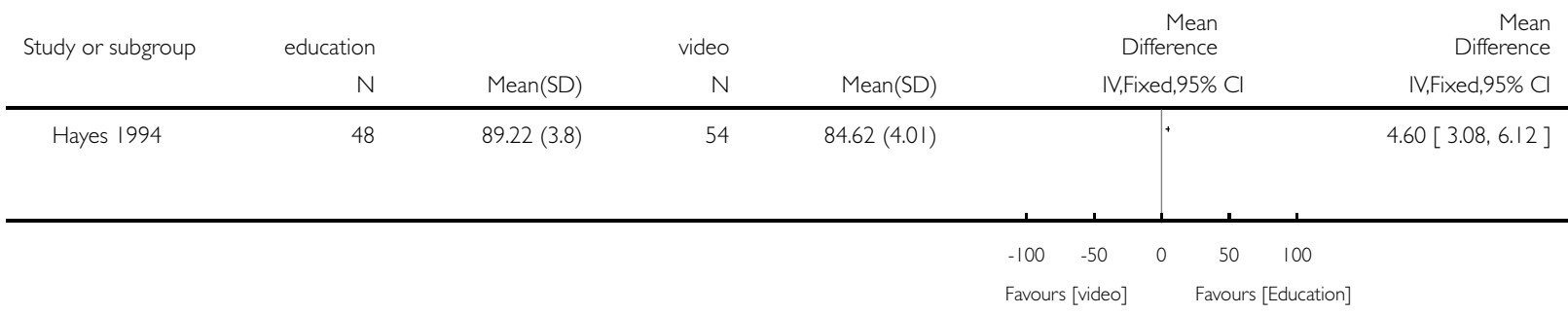

Analysis 6.I. Comparison 6 E-learning versus classroom teaching, Outcome I Correct classification of pressure ulcer photographs.

Review: Education of healthcare professionals for preventing pressure ulcers

Comparison: 6 E-learning versus classroom teaching

Outcome: I Correct classification of pressure ulcer photographs

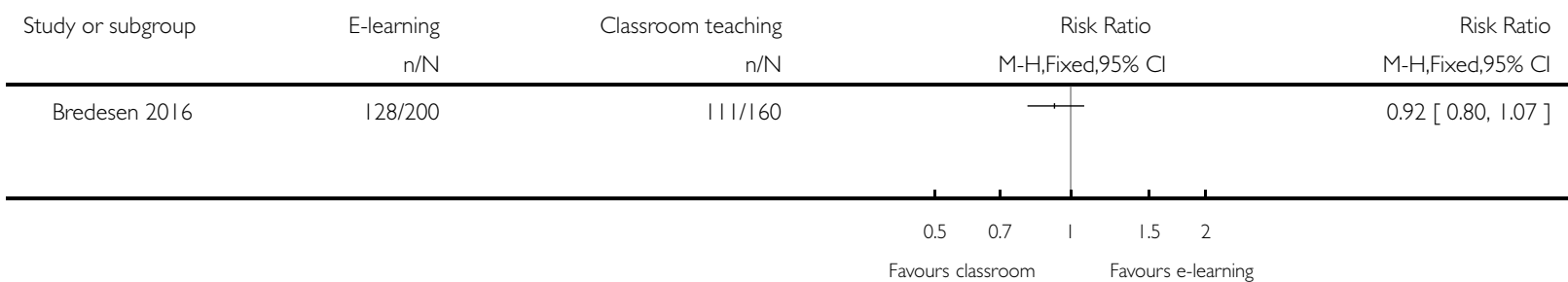




\section{A P P E N D I C E S}

\section{Appendix I. Appendix I: Search Strategies}

\section{Cochrane Wounds Specialised Register}

1 MESH DESCRIPTOR Education, Professional EXPLODE ALL AND INREGISTER

2 MESH DESCRIPTOR Education, Continuing EXPLODE ALL AND INREGISTER

3 (professional* near5 (educat* or training)) AND INREGISTER

4 ((educat* or training) near5 professional*) AND INREGISTER

5 ((nurs* or doctor* $^{*}$ or physiotherap* or therapist* or surgeon* ${ }^{*}$ domiciliar* or practitioner*) near5 (educat* or training)) AND INREGISTER

6 ((educat* or training) near5 (nurs* or doctor* or physiotherap* or therapist* or surgeon* or domiciliar* or practitioner*)) AND INREGISTER

7 ((“Allied Health Occupation*” or "Health Occupation*”) near5 (educat* or training)) AND INREGISTER

8 (educat* or training) near5 ("Allied Health Occupation*” or "Health Occupation*”) AND INREGISTER

9 ((education* or training) next program*) AND INREGISTER

10 (program* next (education* or training)) AND INREGISTER

11 (seminar* or workshop* or course* or open learning) AND INREGISTER

12 ((written or printed or oral) next information) AND INREGISTER

13 information next (written or printed or oral) AND INREGISTER

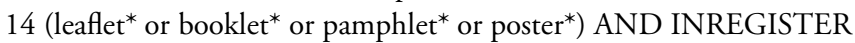

15 \#1 OR \#2 OR \#3 OR \#4 OR \#5 OR \#6 OR \#7 OR \#8 OR \#9 OR \#10 OR \#11 OR \#12 OR \#13 OR \#14

16 MESH DESCRIPTOR Pressure Ulcer EXPLODE ALL AND INREGISTER

17 (pressure next (ulcer* or sore* or injur*)) AND INREGISTER

18 ((ulcer* or sore* or injur*) next pressure) AND INREGISTER

19 (decubitus next (ulcer* or sore*)) AND INREGISTER

20 ((ulcer* ${ }^{*}$ or sore*) next decubitus) AND INREGISTER

21 ((bed next sore $\left.^{*}\right)$ or bedsore*) AND INREGISTER

22 \#17 OR \#16 OR \#18 OR \#19 OR \#20 OR \#21

23 \#15 AND \#22

The Cochrane Central Register of Controlled Clinical Trials (CENTRAL)

\#1 MeSH descriptor: [Education, Professional] explode all trees

\#2 MeSH descriptor: [Education, Continuing] explode all trees

\#3 (professional* near/5 (educat* or training)):ti,ab,kw

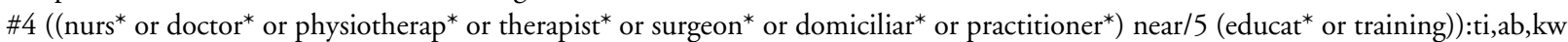
\#5 ((“Allied Health Occupation*” or "Health Occupation*”) near/5 (educat* or training)):ti,ab,kw

\#6 ((education* or training) next program*):ti,ab,kw

\#7 (seminar* or workshop* or course* or open learning):ti,ab,kw

\#8 ((written or printed or oral) next information):ti,ab,kw

\#9 (leaflet* ${ }^{*}$ or booklet* or pamphlet* or poster*):ti,ab,kw

\#10 \{or \#1-\#9\}

\#11 MeSH descriptor: [Pressure Ulcer] explode all trees

\#12 (pressure next (ulcer* ${ }^{*}$ or sore* or injur*)):ti,ab,kw

\#13 (decubitus next (ulcer* or sore*)):ti,ab,kw

\#14 ((bed next sore*) or bedsore*):ti,ab,kw

\#15 \{or \#11-\#14\}

$\# 16$ and \#10,\#15\} in Trials

Ovid MEDLINE

1. exp Education, Professional/

2. exp Education, Continuing/

3. (professional* adj5 (educat* or training)).tw.

4. ((nurs* or doctor* $^{*}$ or physiotherap* or therapist* or surgeon* ${ }^{*}$ or domiciliar* or practitioner*) adj5 (educat* or training)).tw.

5. ((“Allied Health Occupation*” or "Health Occupation*”) adj5 (educat* or training)).tw.

Education of healthcare professionals for preventing pressure ulcers (Review) 
6. ((education* or training) adj program* ${ }^{*}$.tw.

7. (seminar* or workshop* or course* or open learning).tw.

8. ((written or printed or oral) adj information).tw.

9. (leaflet* or booklet* or pamphlet* or poster*).tw.

10. or/1-9

11. exp Pressure Ulcer/

12. (pressure adj (ulcer* or sore* or injur*)).tw.

13. (decubitus adj (ulcer* or sore*)).tw.

14. (bedsore* or bed sore*).tw.

15. or/11-14

16. and $/ 10,15$

17. randomised controlled trial.pt.

18. controlled clinical trial.pt.

19. randomi?ed.ab.

20. placebo.ab.

21. clinical trials as topic.sh.

22. randomly.ab.

23. trial.ti.

24. or/17-23

25. exp animals/ not humans.sh.

26. 24 not 25

27. 16 and 26

\section{Ovid Embase}

1 exp Allied health education/

2 exp Vocational education/

3 exp Clinical education/

4 exp Education, Continuing/

5 (professional* adj5 (educat* or training)).tw.

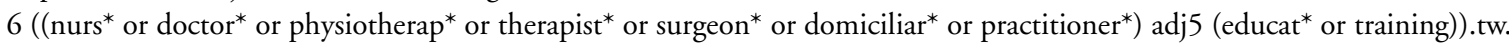

7 ((“Allied Health Occupation*” or "Health Occupation*”) adj5 (educat* or training)).tw.

8 ((education* or training) adj program*).tw.

9 (seminar* or workshop* or course* or open learning).tw.

10 ((written or printed or oral) adj information).tw.

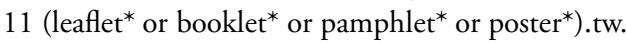

12 or/ $1-11$

13 exp Pressure Ulcer/

14 (pressure adj (ulcer* or sore* or injur*)).tw.

15 (decubitus adj (ulcer* or sore*)).tw.

16 (bedsore* or bed sore*).tw.

17 or/13-16

18 and/12,17

19 Randomized controlled trials/

20 Single-Blind Method/

21 Double-Blind Method/

22 Crossover Procedure/

23 (random* or factorial* or crossover* or cross over* or cross-over* or placebo* or assign* or allocat* or volunteer*).ti,ab.

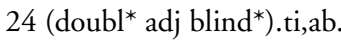

25 (singl* $^{*}$ adj blind*).ti,ab.

26 or/19-25

27 exp animals/ or exp invertebrate/ or animal experiment/ or animal model/ or animal tissue/ or animal cell/ or nonhuman/ 28 human/ or human cell/

29 and $/ 27-28$

3027 not 29

Education of healthcare professionals for preventing pressure ulcers (Review)

Copyright ( 2018 The Cochrane Collaboration. Published by John Wiley \& Sons, Ltd. 
3126 not 30

3218 and 31

\section{EBSCO CINAHL Plus}

S31 S17 AND S30

S30 S 18 OR S 19 OR S20 OR S 21 OR S22 OR S23 OR S24 OR S25 OR S26 OR S27 OR S28 OR S29

S29 TI allocat* random* or AB allocat* random*

S28 MH "Quantitative Studies"

S27 TI placebo* or AB placebo*

S26 MH "Placebos"

S25 TI random* allocat* or AB random* allocat*

S24 MH "Random Assignment"

S23 TI randomi?ed control* trial $^{*}$ or $\mathrm{AB}$ randomi?ed control* trial $^{*}$

S22 AB ( singl* or doubl* or trebl* or tripl*) and AB ( blind* or mask* ${ }^{*}$ )

S21 TI ( singl* or doubl* or trebl* or tripl* ${ }^{*}$ ) and TI (blind* or mask*)

S20 TI clinic* N1 trial* or AB clinic* N1 trial*

S19 PT Clinical trial

S18 MH "Clinical Trialst"

S17 S11 AND S16

S16 S12 OR S13 OR S14 OR S15

S15 TI decubitus or AB decubitus

S14 TI ( bed sore* or bedsore* ) or AB ( bed sore* or bedsore*

S13 TI ( pressure ulcer* or pressure sore* ${ }^{*}$ or AB ( pressure ulcer* or pressure sore* $)$

S12 (MH "Pressure Ulcer+")

S11 S1 OR S2 OR S3 OR S4 OR S5 OR S6 OR S7 OR S8 OR S9 OR S10

S10 TI ( leaflet* or booklet* or pamphlet* or poster*) OR AB ( leaflet* or booklet* or pamphlet* or poster*)

S9 TI ( "written information" or "printed information" or "oral information") OR AB ( "written information" or "printed information" or "oral information")

S8 TI ( seminar* or workshop* or course* or "open learning” ) OR AB ( seminar* or workshop* or course* or "open learning”)

S7 TI ( education* program* $^{*}$ or training program* ${ }^{*}$ OR AB ( education* program* or training program*)

S6 TI ("Allied Health Occupation*" or "Health Occupation*" n5 (educat* or training)) or AB (“Allied Health Occupation*” or "Health Occupation*” n5 (educat* or training))

S5 TI ((nurs* or doctor* or physiotherap* or therapist* or surgeon* or domiciliar* or practitioner*) n5 (educat* or training)) or AB ( (nurs* or doctor* or physiotherap* or therapist* or surgeon* or domiciliar* or practitioner*) n5 (educat* or training))

S4 TI ( professional* N5 (educat* or training) ) OR AB ( professional* N5 (educat* or training))

S3 (MH "Education, Allied Health+")

S2 (MH "Education, Health Sciences+")

S1 (MH "Education, Continuing+")

US National Institutes of Health Ongoing Trials Register (ClinicalTrials.gov)

"education" AND "pressure ulcer"

"education" AND "pressure ulcer prevention"

"healthcare professional" AND "pressure ulcer"

"healthcare professional" AND "pressure ulcer prevention"

World Health Organization International Clinical Trials Registry Platform

"pressure ulcers" AND "education” AND "healthcare professional”

"pressure ulcer prevention" AND "education" and "healthcare professional"

Education of healthcare professionals for preventing pressure ulcers (Review) 


\section{Appendix 2. Appendix 2: Assessment of risk of bias (individually randomised controlled trials)}

\section{Was the allocation sequence randomly generated?}

\section{Low risk of bias}

The investigators describe a random component in the sequence generation process such as: referring to a random number table; using a computer random number generator; coin tossing; shuffling cards or envelopes; throwing dice; drawing of lots.

\section{High risk of bias}

The investigators describe a non-random component in the sequence generation process. Usually, the description would involve some systematic, non-random approach, for example: sequence generated by odd or even date of birth; sequence generated by some rule based on date (or day) of admission; sequence generated by some rule based on hospital or clinic record number.

\section{Unclear}

Insufficient information about the sequence generation process to permit judgement of low or high risk of bias.

\section{Was the treatment allocation adequately concealed?}

\section{Low risk of bias}

Participants and investigators enrolling participants could not foresee assignment because one of the following, or an equivalent method, was used to conceal allocation: central allocation (including telephone, web-based and pharmacy-controlled randomisation); sequentially-numbered drug containers of identical appearance; sequentially-numbered, opaque, sealed envelopes.

\section{High risk of bias}

Participants or investigators enrolling participants could possibly foresee assignments and thus introduce selection bias, such as allocation based on: use of an open random allocation schedule (e.g. a list of random numbers); assignment envelopes without appropriate safeguards (e.g. envelopes were unsealed, non-opaque or not sequentially numbered); alternation or rotation; date of birth; case record number; any other explicitly unconcealed procedure.

\section{Unclear}

Insufficient information to permit judgement of low or high risk of bias. This is usually the case if the method of concealment is not described or not described in sufficient detail to allow a definite judgement, for example if the use of assignment envelopes is described, but it remains unclear whether envelopes were sequentially numbered, opaque and sealed.

\section{Blinding - was knowledge of the allocated interventions adequately prevented during the study?}

\section{Low risk of bias}

Any one of the following.

1. No blinding, but the review authors judge that the outcome and the outcome measurement are not likely to be influenced by lack of blinding.

2. Blinding of participants and key study personnel ensured, and unlikely that the blinding could have been broken.

3. Either participants or some key study personnel were not blinded, but outcome assessment was blinded and the non-blinding of others unlikely to introduce bias. 


\section{High risk of bias}

Any one of the following.

1. No blinding or incomplete blinding, and the outcome or outcome measurement is likely to be influenced by lack of blinding.

2. Blinding of key study participants and personnel attempted, but likely that the blinding could have been broken.

3. Either participants or some key study personnel were not blinded, and the non-blinding of others likely to introduce bias.

\section{Unclear}

Either of the following.

1. Insufficient information to permit judgement of low or high risk of bias.

2. The study did not address this outcome.

\section{Were incomplete outcome data adequately addressed?}

\section{Low risk of bias}

Any one of the following.

1. No missing outcome data.

2. Reasons for missing outcome data unlikely to be related to true outcome (for survival data, censoring unlikely to be introducing bias).

3. Missing outcome data balanced in numbers across intervention groups, with similar reasons for missing data across groups.

4. For dichotomous outcome data, the proportion of missing outcomes compared with observed event risk not enough to have a clinically relevant impact on the intervention effect estimate.

5. For continuous outcome data, plausible effect size (difference in means or standardised difference in means) among missing outcomes not enough to have a clinically relevant impact on observed effect size.

6. Missing data have been imputed using appropriate methods.

\section{High risk of bias}

Any one of the following.

1. Reason for missing outcome data likely to be related to true outcome, with either imbalance in numbers or reasons for missing data across intervention groups.

2. For dichotomous outcome data, the proportion of missing outcomes compared with observed event risk enough to induce clinically relevant bias in intervention effect estimate.

3. For continuous outcome data, plausible effect size (difference in means or standardised difference in means) among missing outcomes enough to induce clinically relevant bias in observed effect size.

4. 'As-treated' analysis done with substantial departure of the intervention received from that assigned at randomisation.

5. Potentially inappropriate application of simple imputation.

\section{Unclear}

Either of the following.

1. Insufficient reporting of attrition/exclusions to permit judgement of low or high risk of bias (e.g. number randomised not stated, no reasons for missing data provided).

2. The study did not address this outcome

\section{Are reports of the study free of suggestion of selective outcome reporting?}

\section{Low risk of bias}

Either of the following:

Education of healthcare professionals for preventing pressure ulcers (Review) 
1. The study protocol is available and all of the study's prespecified (primary and secondary) outcomes that are of interest in the review have been reported in the prespecified way.

2. The study protocol is not available, but it is clear that the published reports include all expected outcomes, including those that were prespecified (convincing text of this nature may be uncommon).

\section{High risk of bias}

Any one of the following.

1. Not all of the study's prespecified primary outcomes have been reported.

2. One or more primary outcomes is reported using measurements, analysis methods or subsets of the data (e.g. subscales) that were not prespecified.

3. One or more reported primary outcomes were not prespecified (unless clear justification for their reporting is provided, such as an unexpected adverse effect).

4. One or more outcomes of interest in the review are reported incompletely so that they cannot be entered in a meta-analysis.

5. The study report fails to include results for a key outcome that would be expected to have been reported for such a study.

\section{Unclear}

Insufficient information to permit judgement of low or high risk of bias. It is likely that the majority of studies will fall into this category.

\section{Other sources of potential bias}

\section{Low risk of bias}

The study appears to be free of other sources of bias.

\section{High risk of bias}

There is at least one important risk of bias. For example, the study:

1. had a potential source of bias related to the specific study design used; or

2. has been claimed to have been fraudulent; or

3. had some other problem.

\section{Unclear}

There may be a risk of bias, but there is either:

1. insufficient information to assess whether an important risk of bias exists; or

2. insufficient rationale or evidence that an identified problem will introduce bias.

\section{Appendix 3. Appendix 3 Risk of bias assessment (cluster randomised controlled trials)}

In cluster-randomised trials, particular biases to consider include: (i) recruitment bias; (ii) baseline imbalance; (iii) loss of clusters; (iv) incorrect analysis; and (v) comparability with individually randomised trials.

(i) Recruitment bias can occur when individuals are recruited to the trial after the clusters have been randomised, as the knowledge of whether each cluster is an 'intervention' or 'control' cluster could affect the types of participants recruited.

(ii) Cluster-randomised trials often randomise all clusters at once, so lack of concealment of an allocation sequence should not usually be an issue. However, because small numbers of clusters are randomised, there is a possibility of chance baseline imbalance between the randomised groups, in terms of either the clusters or the individuals. Although not a form of bias as such, the risk of baseline differences can be reduced by using stratified or pair-matched randomisation of clusters. Reporting of the baseline comparability of clusters, or statistical adjustment for baseline characteristics, can help reduce concern about the effects of baseline imbalance. 
(iii) Occasionally, complete clusters are lost from a trial, and have to be omitted from the analysis. Just as for missing outcome data in individually randomised trials, this may lead to bias. In addition, missing outcomes for individuals within clusters may also lead to a risk of bias in cluster-randomised trials.

(iv) Many cluster-randomised trials are analysed by incorrect statistical methods, not taking the clustering into account. Such analyses create a 'unit of analysis error' and produce over-precise results (the standard error of the estimated intervention effect is too small) and $P$ values that are too small. They do not lead to biased estimates of effect. However, if they remain uncorrected, they will receive too much weight in a meta-analysis.

(v) In a meta-analysis including both cluster and individually randomised trials, or including cluster-randomised trials with different types of clusters, possible differences between the intervention effects being estimated need to be considered. For example, in a vaccine trial of infectious diseases, a vaccine applied to all individuals in a community would be expected to be more effective than if the vaccine was applied to only half of the people. Another example is provided by a Cochrane Review of hip protectors. The cluster trials showed large positive effect, whereas individually randomised trials did not show any clear benefit. One possibility is that there was a herd effect' in the cluster-randomised trials (which were often performed in nursing homes, where compliance with using the protectors may have been enhanced). In general, such 'contamination' would lead to underestimates of effect. Thus, if an intervention effect is still demonstrated despite contamination in those trials that were not cluster-randomised, a confident conclusion about the presence of an effect can be drawn. However, the size of the effect is likely to be underestimated. Contamination and 'herd effects' may be different for different types of cluster.

\section{CONTRIBUTIONS OFAUTHORS}

Alison Porter-Armstrong: co-ordinated and developed the review; extracted data; checked the quality of data extraction; analysed and interpreted data; completed the first draft of the review; contributed to writing and editing the review, approved the final version prior to submission; and is a guarantor of the review.

Zena Moore: extracted data, checked the quality of data extraction, analysed and interpreted data; contributed to writing and editing the review; advised on the review; and approved the final version of the review prior to submission.

Ian Bradbury: advised on statistical analysis of the review; and approved the final version of the review prior to submission.

Suzanne McDonough: undertook and checked quality assessment; contributed to writing and editing the review; advised on the review; and approved the final version of the review prior to submission.

\section{Contributions of editorial base:}

Julie Bruce (Editor): edited the protocol, advised on methodology, interpretation and protocol content; approved the final protocol prior to publication.

Gill Norman (Editor): edited the review, advised on methodology, interpretation and review content; approved the final review prior to publication.

Gill Rizzello (Managing Editor): co-ordinated the editorial process; advised on interpretation and content, and edited the review. Amanda Briant, Reetu Child and Naomi Shaw (Information Specialists): designed the search strategy; edited the search methods section and ran the searches.

Ursula Gonthier (Editorial Assistant): edited the Plain Language Summary and reference section of the review.

Education of healthcare professionals for preventing pressure ulcers (Review) 


\section{DECLARATIONSOF INTEREST}

Alison Porter-Armstrong: received Cochrane Fellowship funding from the HSC Research and Development Division of the Public Health Agency (Northern Ireland) to perform this review.

Zena Moore: received honoraria for speaking at professional meetings for 3M, Molnlycke and Smith \& Nephew.

Ian Bradbury: none known.

Suzanne McDonough: none known.

\section{SOURCES OF SUPPORT}

\section{Internal sources}

- No sources of support supplied

\section{External sources}

- The HSC Research and Development Division of the Public Health Agency (Northern Ireland), UK. Cochrane Fellowship Funding Award for Dr Alison Porter-Armstrong

- This project was supported by the National Institute for Health Research, via Cochrane Infrastructure funding to Cochrane Wounds. The views and opinions expressed therein are those of the authors and do not necessarily reflect those of the Systematic Reviews Programme, NIHR, NHS or the Department of Health, UK.

\section{DIFFERENCES BETWEEN PROTOCOL AND REVIEW}

We planned to compare treatments using the change in knowledge from pre-treatment values. However, this proved impossible because of the way results were reported in the primary publications, and so we made the post-hoc decision to report instead differences in post-treatment levels of knowledge. The protocol did not specify methods for assessing risk of bias in cluster randomised controlled trials. We conducted that assessment using the wounds group template (Appendix 3).

Education of healthcare professionals for preventing pressure ulcers (Review) 